\title{
Novel drug candidates for treating esophageal carcinoma: A study on differentially expressed genes, using connectivity mapping and molecular docking
}

\author{
YU-TING CHEN, JIA-YI XIE, QI SUN and WEI-JIA MO
}

\author{
Department of Pathology, First Affiliated Hospital of Guangxi Medical University, Nanning, Guangxi 530021, P.R. China
}

Received August 8, 2018; Accepted October 23, 2018

DOI: $10.3892 /$ ijo.2018.4618

\begin{abstract}
Patients with esophageal carcinoma (ESCA) have a poor prognosis and high mortality rate. Although standard therapies have had effect, there is an urgent requirement to develop novel options, as increasing drug tolerance has been identified in clinical practice. In the present study, differentially expressed genes (DEGs) of ESCA were identified in The Cancer Genome Atlas and Genotype-Tissue Expression databases. Functional and protein-protein interaction (PPI) analyses were performed. The Connectivity Map (CMAP) was selected to predict drugs for the treatment of ESCA, and their target genes were acquired from the Search Tool for Interactions of Chemicals (STITCH) by uploading the Simplified Molecular-Input Line-Entry System structure. Additionally, significant target genes and ESCA-associated hub genes were extracted using another PPI analysis, and the corresponding drugs were added to construct a network. Furthermore, the binding affinity between predicted drug candidates and ESCA-associated hub genes was calculated using molecular docking. Finally, 827 DEGs ( $\left(\log _{2}\right.$ fold-changel $\geq 2$; q-value $<0.05$ ), which are principally involved in protein digestion and absorption $(\mathrm{P}<0.005)$, the plasminogen-activating cascade $(\mathrm{P}<0.01)$, as well as the 'biological regulation' of the Biological Process, 'membrane' of the Cellular Component
\end{abstract}

Correspondence to: Dr Wei-Jia Mo, Department of Pathology, First Affiliated Hospital of Guangxi Medical University, 6 Shuangyong Road, Nanning, Guangxi 530021, P.R. China

E-mail: gxmumoweijia@163.com

Abbreviations: ESCA, esophageal carcinoma; DEG, differentially expressed genes; TCGA, The Cancer Genome Atlas; GTEx, Genotype-Tissue Expression; PPI, protein-protein interaction; CMAP, Connectivity Map; KEGG, Kyoto Encyclopedia of Genes and Genomes; GO, Gene Ontology; BP, Biological Process; CC, Cellular Component; MF, Molecular Function; STITCH, Search Tool for Interactions of Chemicals; SMILES, Simplified Molecular-Input Line-Entry System

Key words: esophageal carcinoma, drug candidates, differentially expressed genes, target genes, functional analysis, Connectivity Map, molecular docking and 'protein binding' of the Molecular Function categories, were obtained. Additionally, 11 hub genes were obtained from the PPI network (all degrees $\geq 30$ ). Furthermore, the 15 first screen drugs were extracted from CMAP (score <-0.85) and the 9 second screen drugs with 70 target genes were extracted from STITCH. Furthermore, another PPI analysis extracted 51 genes, and apigenin, baclofen, Prestwick-685, menadione, butyl hydroxybenzoate, gliclazide and valproate were selected as drug candidates for ESCA. Those molecular docking results with a docking score of $>5.52$ indicated the significance of apigenin, Prestwick-685 and menadione. The results of the present study may lead to novel drug candidates for ESCA, among which Prestwick-685 and menadione were identified to be significant new drug candidates.

\section{Introduction}

Esophageal carcinoma (ESCA) is one of the most common types of cancer in the digestive system which primarily includes esophageal squamous cell carcinoma (ESCC) and esophageal adenocarcinoma (1). According to recent statistics, estimated new cases of and mortality from ESCA account for a large proportion of all cancer in the USA (2). ESCA also ranks in the top ten of cancer incidence and mortality rate worldwide, which is associated with genetic and environmental factors (3). In addition, patients with ESCA have a poor prognosis and high mortality rate that may be associated with glucose-regulated protein $78(4,5)$.

At present, several methods are practiced in clinical treatment for ESCA (6). Surgical resection is commonly used to remove cancerous tissue and leads to an improved survival rate. Neoadjuvant chemotherapy (without radiation therapy) provides an improved survival benefit compared with surgery alone (7), but the effects on local control are unclear. Tri-modality treatment (concomitant chemotherapy and radiation therapy followed by surgery) also has a marked effect compared with surgery alone (5). Additionally, several chemotherapy target agents for ESCA have been reported, including fluoropyrimidines [5-fluorouracil (5-FU) and capecitabine], platinum agents (cisplatin and oxaliplatin), taxanes (paclitaxel and docetaxel), irinotecan, mitomycin-C, anthracyclines, methotrexate, vinorelbine and gemcitabine. The combination of two or more drugs has a more marked reaction, as it has been reported to increase the efficacy of chemoradiotherapy in patients with 
ESCA (8-10). However, intolerance of fluoropyrimidine-based, platinum-based and taxane-based chemotherapy has also been identified in patients, and immune checkpoint blockade therapy remains under investigation (11). Therefore, further research is required for more effective therapeutic methods.

Gene-associated therapy for cancers has become a research focus in recent years (12-16). With regard to ESCA, it was identified that the aberrant transcription and translation of genes affect the synthesis of associated proteins, which has an effect on the corresponding physiological processes, and consequently influences the diagnosis and prognosis of ESCA (17-19). It was also identified that the chemotherapeutic mechanism of ESCA was associated with upregulation and downregulation of genes or DNA repair genes $(20,21)$. In addition, gene levels and certain signaling pathways were identified to be associated with chemotherapy resistance $(22,23)$. For example, it was reported that the expression of myeloid cell leukemia 1 in ESCA cancerous tissue with cisplatin resistance increased in comparison with that in normal tissue (24). Let-7 was also identified to serve a potentially positive function in patients with 5-FU resistance (25), which indicates that the drugs targeted in these pathways or genes are potential candidates for improved treatment. Generally, differentially expressed genes (DEGs) and signaling pathways may be the fundamental reason for the development of ESCA. Thus, research into the biological significance of target genes and their corresponding signaling pathways is required for gene-associated chemotherapy.

However, specific drugs mapped to the target genes and their associated pathways remain unknown. Thus, the aim of the present study was to predict novel drug candidates of ESCA using bioinformatics analysis, which was principally based on the Connectivity Map (CMAP), a database that contains 1,309 Food and Drug Administration-approved small molecules and 7,000 gene expression profiles, and has been widely used to reveal the mechanism of drugs (26). Furthermore, molecular virtual docking was used in the search for matching predicted potential drugs and screened proteins. To a certain extent, the present study may provide a new point of reference for chemotherapy for ESCA, with regard to its molecular biology and the methodology.

\section{Materials and methods}

Acquisition of DEGs in ESCA. To acquire the information of gene expression levels in ESCA, the gene expression data of ESCA were downloaded from The Cancer Genome Atlas (TCGA) and Genotype-Tissue Expression (GTEx) (27), and the edition of TCGA dataset on ESCA was updated on October 13, 2017. The gene expression data of ESCA were normalized into the transcripts per million reads format. The differential expression analysis was further performed on the basis of the normalized data and analysis of variance (ANOVA), which was used for tumor vs. paired normal samples. For the differential analysis methods of ANOVA, genes with $1 \log _{2}$ fold-change (FC) $\mid \geq 2$ and $q$-value $<0.05$ were considered to be DEGs.

\section{Analysis of DEGs associated with ESCA}

Functional analysis of differentially expressed genes. WEB-based GEne SeT AnaLysis Toolkit (Webgestalt; www.

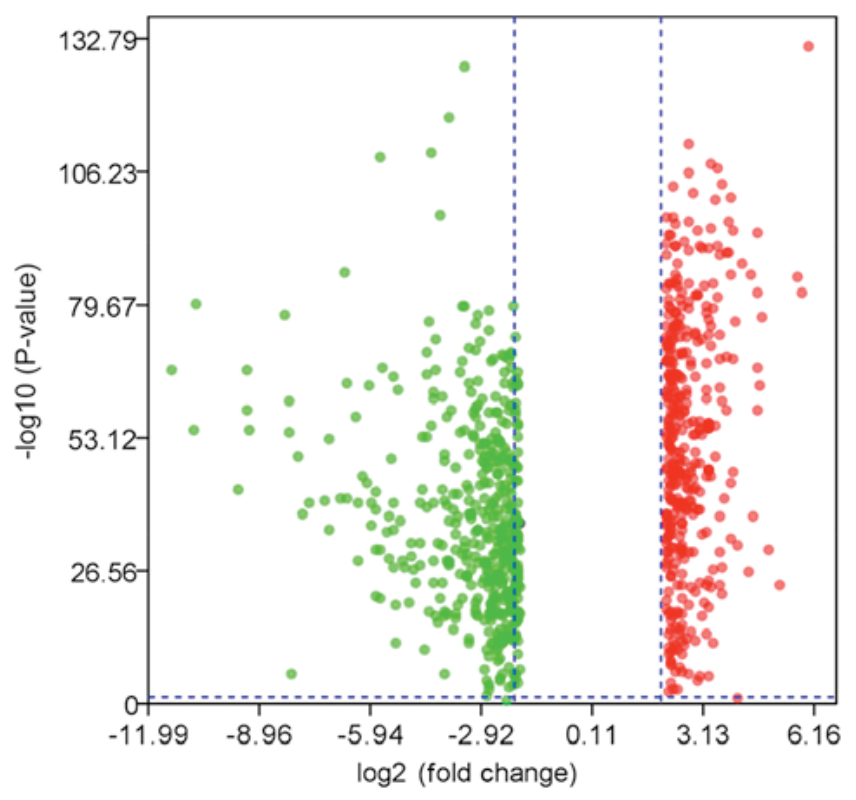

Figure 1. Volcano plot of differentially expressed genes between esophageal carcinoma and normal tissues.

webgestalt.org) was used to explain the function of extracted DEGs with an enrichment method of over-representation (enrichment) analysis. Gene Ontology (GO) enrichment analysis was performed to classify the genes into their Biological Process (BP), Cellular Component (CC) and Molecular Function (MF) categories. The Kyoto Encyclopedia of Genes and Genomes (KEGG) (www. kegg.jp) and Protein Annotation Through Evolutionary Relationships (PANTHER) (www.pantherdb.org) analyses were performed to determine the pathways in which the DEGs were significantly involved (28-30).

Excavation of hub genes of ESCA. For further understanding of genes that may have a significant effect on ESCA, the protein-protein interaction (PPI) network was then drafted via Search Tool for the Retrieval of Interacting Genes (STRING; string-db.org). The interaction between two nodes, which represent two genes, was confirmed using Textmining, Experiments, Databases, Co-expression, Neighborhood, Gene Fusion and Co-occurrence. Degrees of edges were calculated using Cytoscape (29,31-34). Finally, the genes with a degree of $\geq 30$ were selected to be hub genes of ESCA, which were considered to be potential bioactive factors for ESCA and were further involved in the subsequent research.

\section{Prediction of ESCA-associated drugs and extraction of relevant target genes}

Drug prediction of ESCA based on CMAP. CMAP (portals. broadinstitute.org/cmap) $(26,28)$ was selected to predict the potential drug molecules for ESCA. Following ID conversion via Affymetrix (www.affymetrix.com/analysis/index.affx), the upregulated and downregulated DEGs were uploaded to CMAP for online analysis. Detailed results from CMAP were downloaded, and the first screening drugs were further acquired following filtering for a score of $<-0.85$.

Extraction of target genes for the first screening drugs. To further screen out more significant drug molecules and prepare 
Table I. Two-time Kyoto Encyclopedia of Genes and Genomes analysis.

\begin{tabular}{|c|c|c|c|c|c|}
\hline Group & Gene set & Description & P-value & FDR & Overlapping genes \\
\hline \multirow[t]{10}{*}{ A } & hsa04974 & Protein digestion and absorption & $2.45 \times 10^{-7}$ & $7.41 \times 10^{-5}$ & $\begin{array}{l}10008,10136,1277,1278,1281,1282,1284 \\
1289,1300,2006,477,5644,5645,643834 \\
643847\end{array}$ \\
\hline & hsa04512 & ECM-receptor interaction & $1.61 \times 10^{-5}$ & $2.44 \times 10^{-3}$ & $\begin{array}{l}1277,1278,1282,1284,3655,3679,3685 \\
3691,375790,3918,6696,7148\end{array}$ \\
\hline & hsa04610 & $\begin{array}{l}\text { Complement and coagulation } \\
\text { cascades }\end{array}$ & $5.86 \times 10^{-5}$ & $5.92 \times 10^{-3}$ & $\begin{array}{l}1675,2149,2151,5054,5055,5265,5328, \\
5329,713,714,730\end{array}$ \\
\hline & hsa05146 & Amebiasis & $1.20 \times 10^{-4}$ & $9.06 \times 10^{-3}$ & $\begin{array}{l}1277,1278,1281,1282,1284,2919,3553, \\
3576,3918,5275,6317,6318\end{array}$ \\
\hline & hsa00590 & Arachidonic acid metabolism & $2.01 \times 10^{-4}$ & $1.22 \times 10^{-2}$ & $\begin{array}{l}100137049,1571,239,247,2878,50487, \\
5320,5730,874\end{array}$ \\
\hline & hsa00982 & $\begin{array}{l}\text { Drug metabolism: } \\
\text { Cytochrome P450 }\end{array}$ & $5.09 \times 10^{-4}$ & $2.04 \times 10^{-2}$ & $\begin{array}{l}125,131,1571,218,222,2327,2946,316, \\
54577\end{array}$ \\
\hline & hsa04062 & Chemokine signaling pathway & $5.22 \times 10^{-4}$ & $2.04 \times 10^{-2}$ & $\begin{array}{l}10563,2919,2921,3576,3579,3627,4067 \\
4283,6358,6362,6363,6364,6366,6373 \\
6772,9560\end{array}$ \\
\hline & hsa04933 & $\begin{array}{l}\text { AGE-RAGE signaling pathway } \\
\text { in diabetic complications }\end{array}$ & $5.38 \times 10^{-4}$ & $2.04 \times 10^{-2}$ & $\begin{array}{l}1277,1278,1281,1282,1284,3383,3553, \\
3576,5054,5292,6772\end{array}$ \\
\hline & hsa00980 & $\begin{array}{l}\text { Metabolism of xenobiotics } \\
\text { by cytochrome } \mathrm{P} 450\end{array}$ & $7.70 \times 10^{-4}$ & $2.59 \times 10^{-2}$ & $\begin{array}{l}125,131,1571,218,222,2946,29785,54577, \\
874\end{array}$ \\
\hline & hsa04060 & $\begin{array}{l}\text { Cytokine-cytokine receptor } \\
\text { interaction }\end{array}$ & $1.42 \times 10^{-3}$ & $4.30 \times 10^{-2}$ & $\begin{array}{l}10563,2919,2921,3553,3576,3579,3624 \\
3627,4233,4283,51330,53833,6358,6362 \\
6363,6364,6366,6373,9560\end{array}$ \\
\hline \multirow[t]{10}{*}{$\mathrm{B}$} & hsa00982 & $\begin{array}{l}\text { Drug metabolism: } \\
\text { Cytochrome P450 }\end{array}$ & $3.84 \times 10^{-7}$ & $1.16 \times 10^{-4}$ & $1548,1555,1559,316,4128,4129,54658$ \\
\hline & hsa05210 & Colorectal cancer & $3.41 \times 10^{-6}$ & $4.02 \times 10^{-4}$ & $207,2353,2932,54205,7157,836$ \\
\hline & hsa04915 & Estrogen signaling pathway & $4.40 \times 10^{-6}$ & $4.02 \times 10^{-4}$ & $207,2099,2353,2550,3763,4318,9568$ \\
\hline & hsa05161 & Hepatitis B & $5.40 \times 10^{-6}$ & $4.02 \times 10^{-4}$ & $207,2185,2353,4318,54205,6772,7157,836$ \\
\hline & hsa00380 & Tryptophan metabolism & $6.63 \times 10^{-6}$ & $4.02 \times 10^{-4}$ & $1545,316,4128,4129,847$ \\
\hline & hsa04668 & TNF signaling pathway & $8.30 \times 10^{-6}$ & $4.19 \times 10^{-4}$ & $207,2353,3553,3627,4318,5743,836$ \\
\hline & hsa05014 & Amyotrophic lateral sclerosis & $2.24 \times 10^{-5}$ & $9.68 \times 10^{-4}$ & $54205,598,7157,836,847$ \\
\hline & hsa04210 & Apoptosis & $4.01 \times 10^{-5}$ & $1.52 \times 10^{-3}$ & $142,207,2353,54205,598,7157,836$ \\
\hline & hsa00590 & Arachidonic acid metabolism & $5.82 \times 10^{-5}$ & $1.96 \times 10^{-3}$ & $1555,1559,5319,5320,5743$ \\
\hline & hsa00830 & Retinol metabolism & $7.32 \times 10^{-5}$ & $2.07 \times 10^{-3}$ & $1548,1555,1559,316,54658$ \\
\hline
\end{tabular}

Group A contains the differentially expressed genes of ESCA ( $\log _{2}$ fold-changel $\geq 2$ ); Group B contains 51 genes including 44 drug candidate-associated target genes and 7 ESCA-associated hub genes. ESCA, esophageal carcinoma; FDR, false discovery rate; ECM, extracellular matrix; AGE, advanced glycation end-products; RAGE, receptor for AGE; TNF, tumor necrosis factor.

for the following investigation of potential drug-associated mechanisms in ESCA, the Search Tool for Interactions of Chemicals (STITCH, stitch.embl.de), a protein-compound interactions database that contains 390,000 compounds and 3.6 million proteins, was used in which the Canonical Simplified Molecular-Input Line-Entry System (SMILES) structure of drugs downloaded from PubChem (pubchem.ncbi.nlm.nih. gov) were uploaded in order to search for target genes. In this way, the second screening drugs were extracted when the drugs without STITCH-predicted results were phased out, and their corresponding target genes were obtained. Additionally, intersection between predicted target genes and the extracted DEGs of ESCA was calculated using FunRich (35) for a preliminary understanding of their associations.
Interaction analysis of drug candidates-target genes-ESCAassociated hub genes. To investigate the associations between the predicted drugs and hub genes of ESCA, the target genes of drugs and hub genes of ESCA were analyzed. First, another PPI network was constructed to analyze the interactions between the two sources of genes aforementioned. Connected nodes, confirmed by experiments and databases, were identified and were considered to be associated genes. The unconnected nodes were not included in the following investigation and their corresponding drugs were eliminated. Up to this point, all the extant drugs were considered to be drug candidates of ESCA in the present study. Furthermore, genes confirmed by PPI were then used for constructing the network of drug candidates-target genes-ESCA-associated hub genes. Further analysis of the 
Table II. Two-time Protein Annotation Through Evolutionary Relationships analysis.

\begin{tabular}{|c|c|c|c|c|c|}
\hline Group & Gene set & Description & P-value & FDR & Overlapping genes \\
\hline \multirow[t]{5}{*}{ A } & P00050 & Plasminogen-activating cascade & $2.39 \times 10^{-7}$ & $2.70 \times 10^{-5}$ & $5328,4312,5055,5054,4314,4318,5329$ \\
\hline & P00011 & Blood coagulation & $1.64 \times 10^{-3}$ & $9.25 \times 10^{-2}$ & $5328,5265,5055,5054,2149,5329$ \\
\hline & P00034 & Integrin signaling pathway & $3.46 \times 10^{-3}$ & $1.30 \times 10^{-1}$ & $\begin{array}{l}10095,1277,1281,1282,3685,1278,1284, \\
3691,1289,3655,1300,3679,3918\end{array}$ \\
\hline & P06959 & CCKR signaling map & $1.55 \times 10^{-2}$ & $4.39 \times 10^{-1}$ & $\begin{array}{l}5328,7031,5055,5054,3685,4067, \\
4314,4316,2919,3576,4953,4318\end{array}$ \\
\hline & P00031 & $\begin{array}{l}\text { Inflammation mediated } \\
\text { by chemokine and cytokine } \\
\text { signaling pathway }\end{array}$ & $1.94 \times 10^{-2}$ & $4.39 \times 10^{-1}$ & $\begin{array}{l}6366,10095,3627,3576,239,3579,4629 \\
6362,72,6364,3710,4776,9560\end{array}$ \\
\hline \multirow[t]{9}{*}{ B } & P06959 & CCKR signaling map & $1.00 \times 10^{-5}$ & $1.14 \times 10^{-3}$ & $\begin{array}{l}2353,2641,4318,6869,207,5743,836, \\
2932,598,2185\end{array}$ \\
\hline & P00006 & Apoptosis signaling pathway & $1.05 \times 10^{-3}$ & $5.93 \times 10^{-2}$ & $2353,7157,207,836,54205,598$ \\
\hline & P00029 & Huntington disease & $1.27 \times 10^{-2}$ & $3.88 \times 10^{-1}$ & $2353,7157,627,207,836$ \\
\hline & P00036 & Interleukin signaling pathway & $1.62 \times 10^{-2}$ & $3.88 \times 10^{-1}$ & $2353,207,6772,2932$ \\
\hline & P04372 & 5-Hydroxytryptamine degradation & $1.71 \times 10^{-2}$ & $3.88 \times 10^{-1}$ & 4128,4129 \\
\hline & P04397 & p53 pathway by glucose deprivation & $2.30 \times 10^{-2}$ & $4.34 \times 10^{-1}$ & 7157,207 \\
\hline & P00001 & $\begin{array}{l}\text { Adrenaline and noradrenaline } \\
\text { biosynthesis }\end{array}$ & $3.69 \times 10^{-2}$ & $4.78 \times 10^{-1}$ & 4128,4129 \\
\hline & P04393 & Ras pathway & $4.36 \times 10^{-2}$ & $4.78 \times 10^{-1}$ & $207,6772,2932$ \\
\hline & P00020 & Fas signaling pathway & $4.76 \times 10^{-2}$ & $4.78 \times 10^{-1}$ & 142,836 \\
\hline
\end{tabular}

Group A contains the differentially expressed genes of ESCA ( $\log _{2}$ fold-changel $\geq 2$ ); Group B contains 51 genes including 44 drug candidate-associated target genes and 7 ESCA-associated hub genes. ESCA, esophageal carcinoma; FDR, false discovery rate; CCKR, cholecystokinin receptor.

selected genes was performed using the same methods as for the aforementioned functional analysis of DEGs of ESCA.

Molecular docking between predicted drug candidates and hub genes. To further investigate the underlying associations between drugs and hub genes in the drug candidates-target genes-ESCA-associated hub genes network, molecular docking was performed using systemsDock (systemsdock.unit.oist. $\mathrm{jp} / \mathrm{iddp} / \mathrm{home} / \mathrm{index}$ ), which is a web server for network pharmacology-based prediction and analysis $(36,37)$. Selected by the second PPI analysis, protein names of the ESCA-associated hub genes in the network were added and specified, then the SMILES structures of drug candidates involved in the network were also uploaded. A protein and a drug were tested each time. The binding affinity between each hub gene and drug groups was predicted by docking scores.

\section{Results}

DEGs of ESCA and functional analysis. A total of 827 DEGs were downloaded from TCGA and GTEx databases with the criteria of $\mid \log 2 \mathrm{FCl} \geq 2$ and q-value $<0.05$ in ANOVA, which includes 375 upregulated genes and 452 downregulated genes (Fig. 1). The following KEGG analysis showed that DEGs were significantly involved in 10 pathways $(\mathrm{P}<0.005)$, particularly in protein digestion and absorption, extracellular matrix-receptor interaction and complement, and coagulation cascades (Table I). A PANTHER analysis indicated that DEGs were significantly involved in five pathways $(\mathrm{P}<0.05)$, among which the plasminogen-activating cascade, blood coagulation and integrin signaling pathway were particularly significant $(\mathrm{P}<0.01$; Table II). Classified by GO enrichment analysis, the DEGs were primarily involved in the 'biological regulation', 'metabolic process' and 'response to stimulus' BP categories, and the 'membrane' and 'vesicle' CC categories. They also were involved in the 'nucleus' $\mathrm{CC}$ category, and in the 'protein binding', 'ion binding' and 'hydrolase activity' MF categories (Fig. 2). Furthermore, 11 genes, including elastin (ELN), tissue inhibitor of matrix metalloproteinase 1 (TIMPI), intercellular adhesion molecule 1 (ICAM1), topoisomerase 2A (TOP2A), interleukin $1 \mathrm{~B}(I L 1 B)$, collagen type I $\alpha 1(C O L 1 A 1), I L 8$, matrix metalloproteinase 9 (MMP9), secreted phosphoprotein 1 $(S P P 1)$, signal transducer and activator of transcription 1 (STAT1) and CXC chemokine ligand 10 (CXCL10), were finally determined to be hub genes following calculation of the edges based on PPI network analysis (all degrees 230 ) (Fig. 3).

ESCA-associated drugs and relevant target genes. Upregulated and downregulated genes from the TCGA and GTEx databases were uploaded to CMAP, then scores of the predicted ESCA-associated drugs were obtained from the detailed results. Drugs that had a score of $<-0.85$ were extracted as the first screening drugs for further research, including verteporfin, apigenin, cefixime, Prestwick-685, menadione, baclofen, dequalinium chloride, butyl hydroxybenzoate, naloxone, paroxetine, acetazolamide, gliclazide, valproic acid 

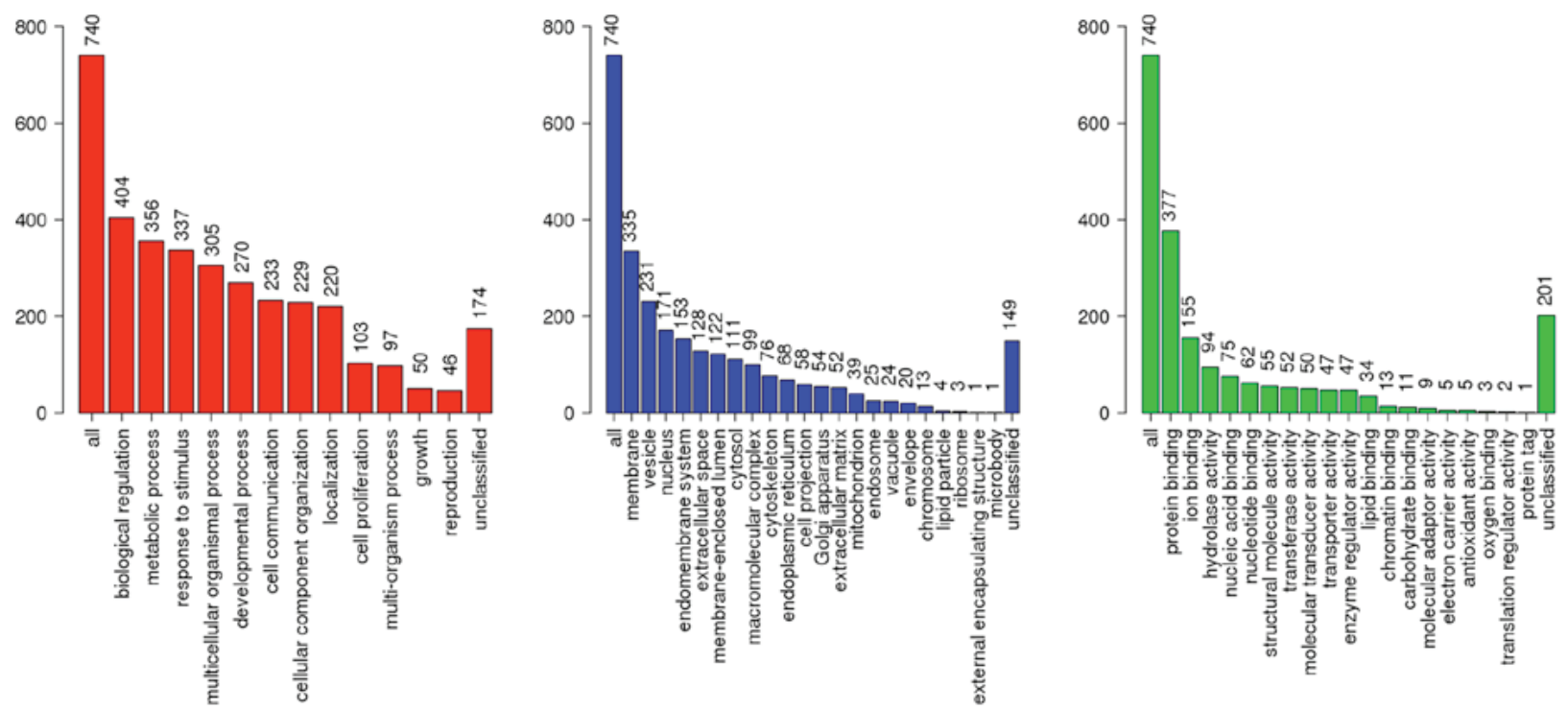

Figure 2. GO analysis of the differentially expressed genes of ESCA ( $\log _{2}$ fold-changel $\left.\geq 2\right)$. Red bars, Biological Process; blue bars, Cellular Component; green bars, Molecular Function. GO, Gene Ontology; ESCA, esophageal carcinoma.

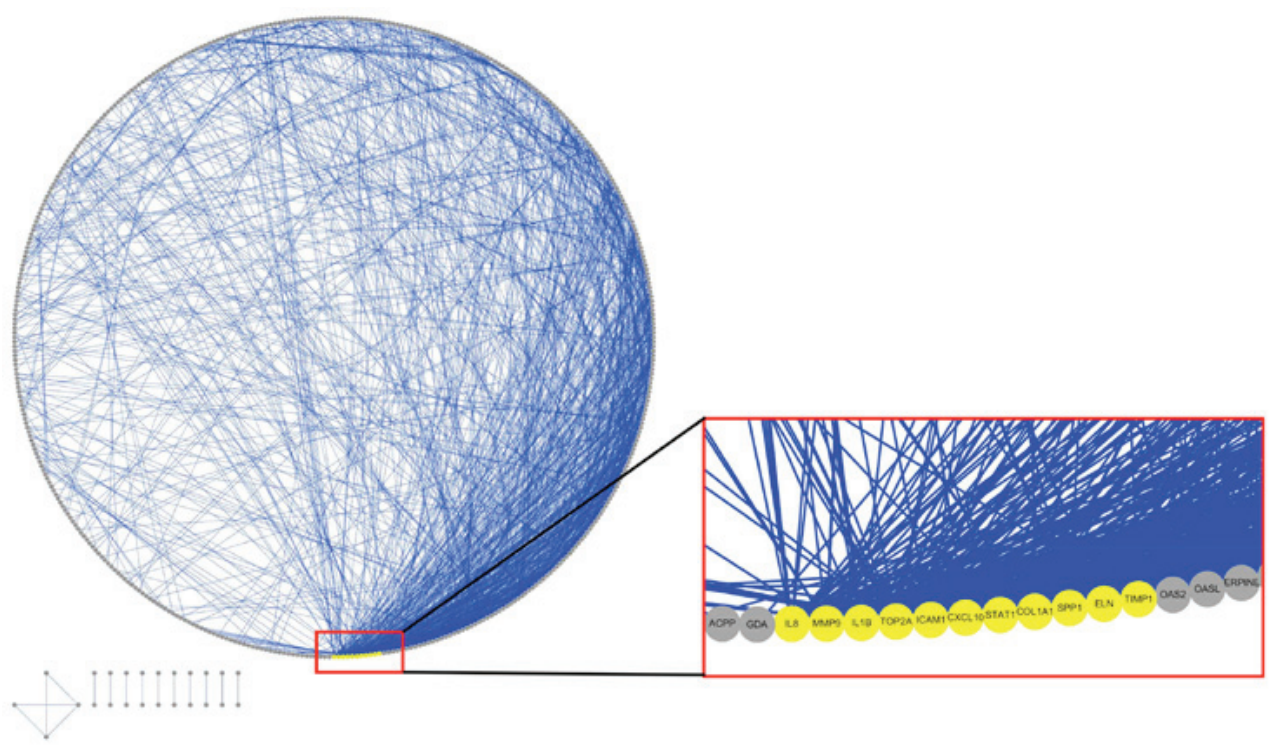

Figure 3. Protein-protein interaction network of differentially expressed genes of esophageal carcinoma based on Search Tool for the Retrieval of Interacting Genes. The network is presented with an attribute circle layout. Blue lines indicate edges between nodes; yellow circles indicate hub gene nodes (ELN, TIMPI, ICAM1, TOP2A, IL1B, COL1A1, IL8, MMP9, SPP1, STAT1 and CXCL10); gray circles indicate other nodes. Hub genes were extracted with all degrees $\geq 30$.

and metacycline (Table III). Furthermore, Prestwick-685 was categorized as clofazimine by PubChem, whereas dequalinium chloride and butyl hydroxybenzoate were also named dequalinium and butylparaben, respectively. On the basis of STITCH, 70 target genes of 9 second screening drugs were acquired (Fig. 4). In addition, as Fig. 5 presents, only four gene intersections were identified in DEGs of ESCA and target genes of the 9 second screening drugs, which was a preliminary indication that no significant difference in expression of the drug-associated target genes in ESCA was identified.

Network of drug candidates-target genes-ESCA-associated hub genes

Gene association analysis. A total of 70 target genes of drugs and 11 hub genes were united for further analysis. Interactions of the relevant genes were identified in the second PPI network. According to Fig. 6 (with the green circles representing target genes of predicted drugs and yellow circles representing the hub genes of ESCA), 51 genes were considered to be connected and met the criteria of having been confirmed by other experiments and databases. Acetazolamide and dequalinium were eliminated because their target genes were considered meaningless through PPI analysis, thus the other 7 drugs which were relevant to the aforementioned 51 genes were consequently considered as drug candidates of ESCA. As indicated in Fig. 7, associations among the 7 predicted drug candidates-target genes-ESCA-associated hub genes were revealed via network construction, in which the red oblongs represent drug candidates, yellow circles represent 44/51 selected genes (which were also target genes of drug 


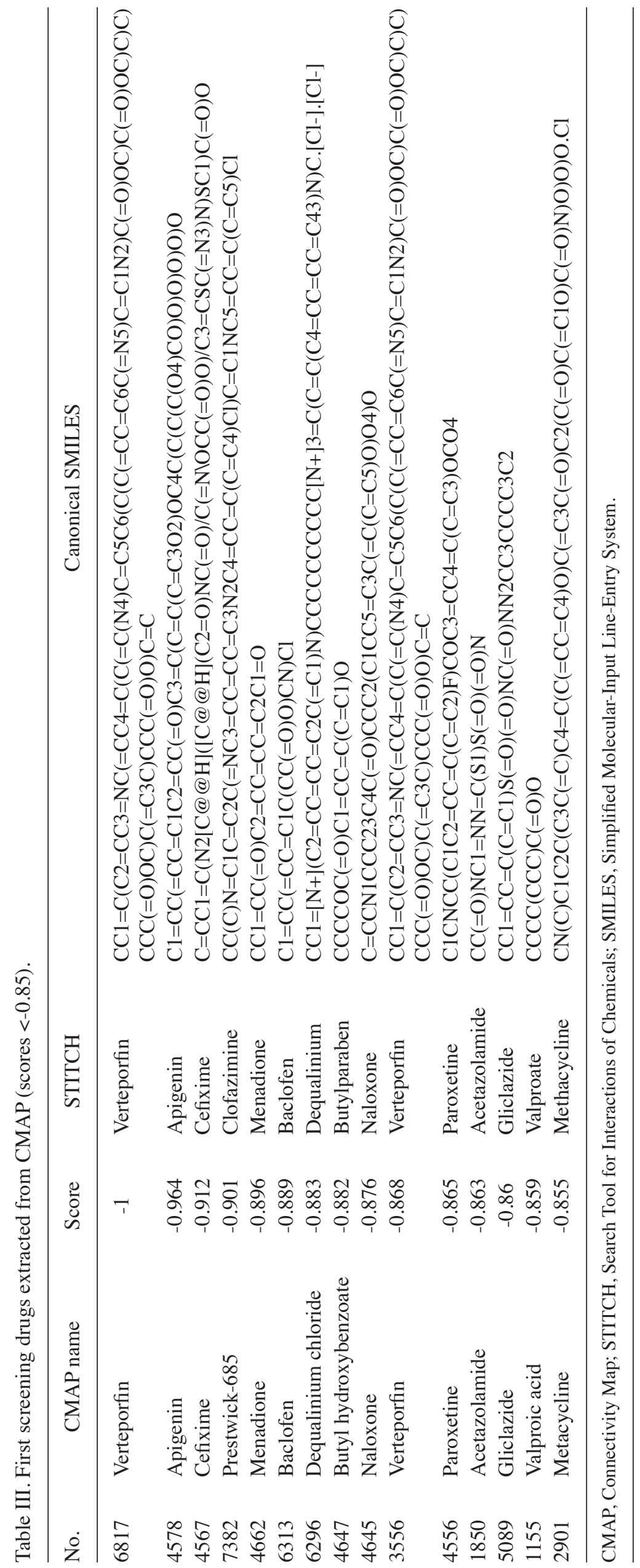


A

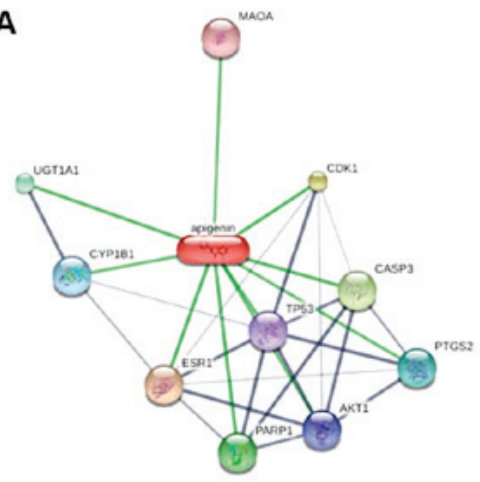

D

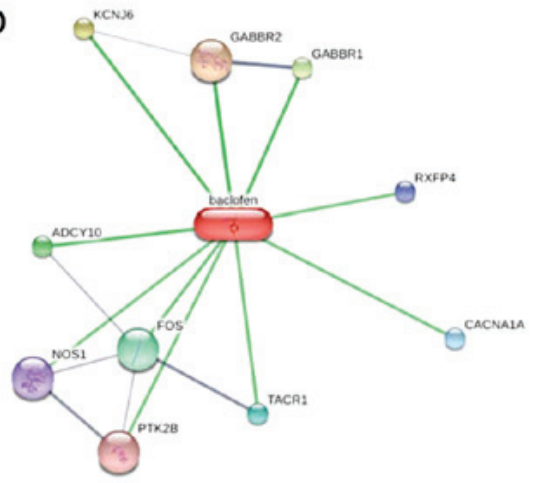

G

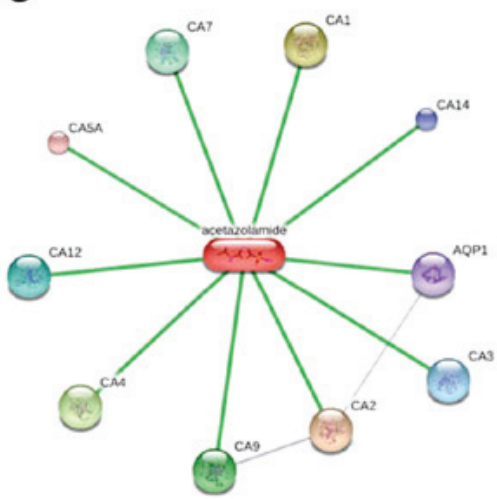

B

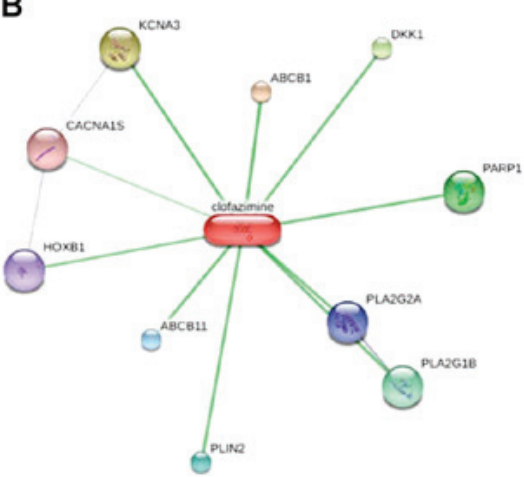

E

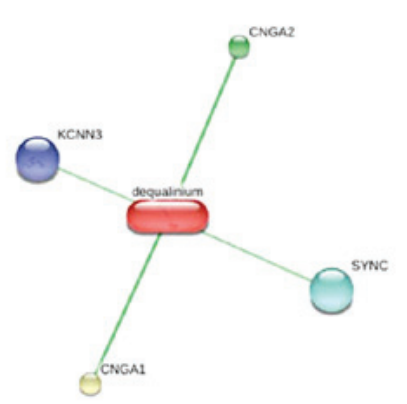

H

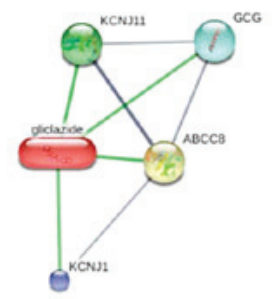

C

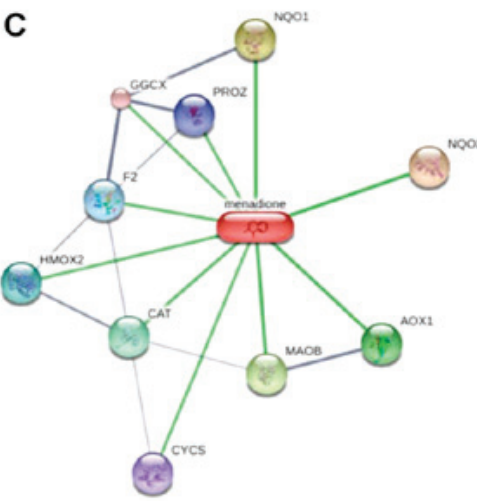

$\mathrm{F}$
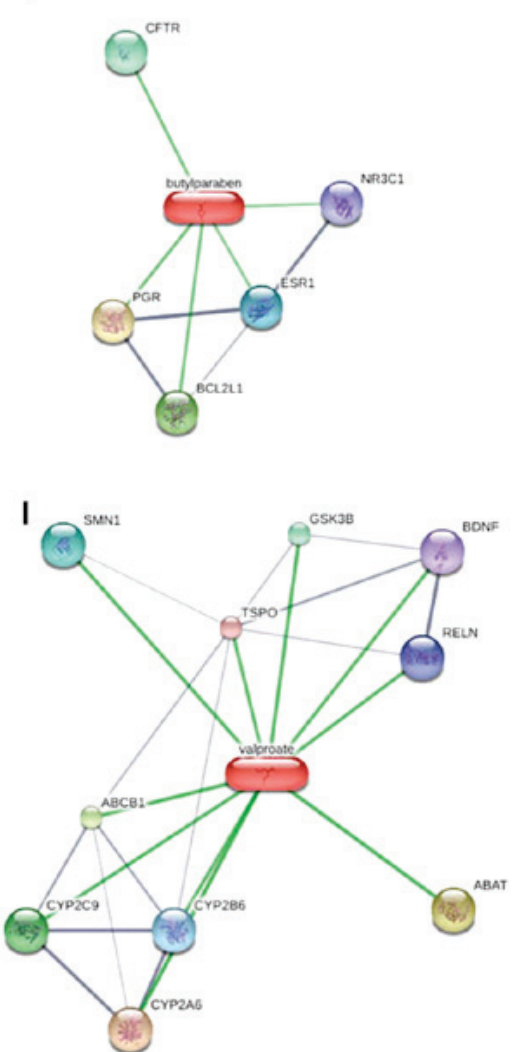

Figure 4. Target genes of 9 second screening drugs based on Search Tool for Interactions of Chemicals. (A) Apigenin; (B) Prestwick-685 (clofazimine); (C) menadione; (D) baclofen; (E) dequalinium chloride (dequalinium); (F) butyl hydroxybenzoate (butylparaben); (G) acetazolamide; (H) gliclazide; (I) valproic acid (valproate).

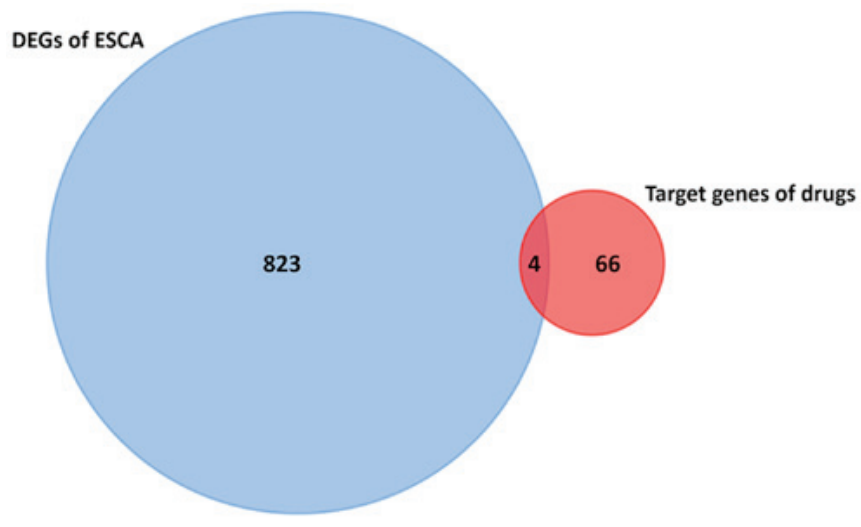

Figure 5. Intersection of 827 DEGs of ESCA and 70 target genes of 9 second screening drugs. DEG, differentially expressed gene; ESCA, esophageal carcinoma. candidates) and blue polygons represent the other 7 genes also belonging to ESCA-associated hub genes.

Functional analysis of genes. The 51 selected genes were identified to participate principally in 10 pathways, including drug metabolism (cytochrome P450), colorectal cancer and the estrogen signaling pathway (Table I), on the basis of KEGG analysis $(\mathrm{P}<0.001)$, as well as 9 pathways on the basis of PANTHER analysis $(\mathrm{P}<0.05)$, which, significantly, included the cholecystokinin receptor (CCKR) signaling map and apoptosis signaling pathway $(\mathrm{P}<0.01$; Table II). GO annotation analysis indicated that the results of BP, CC, and MF classification were almost the same as the results of the previous analysis for DEGs of ESCA (Fig. 8). At this point, although 66/70 drug-associated target genes were not differentially expressed in ESCA, they may be regulated by several 


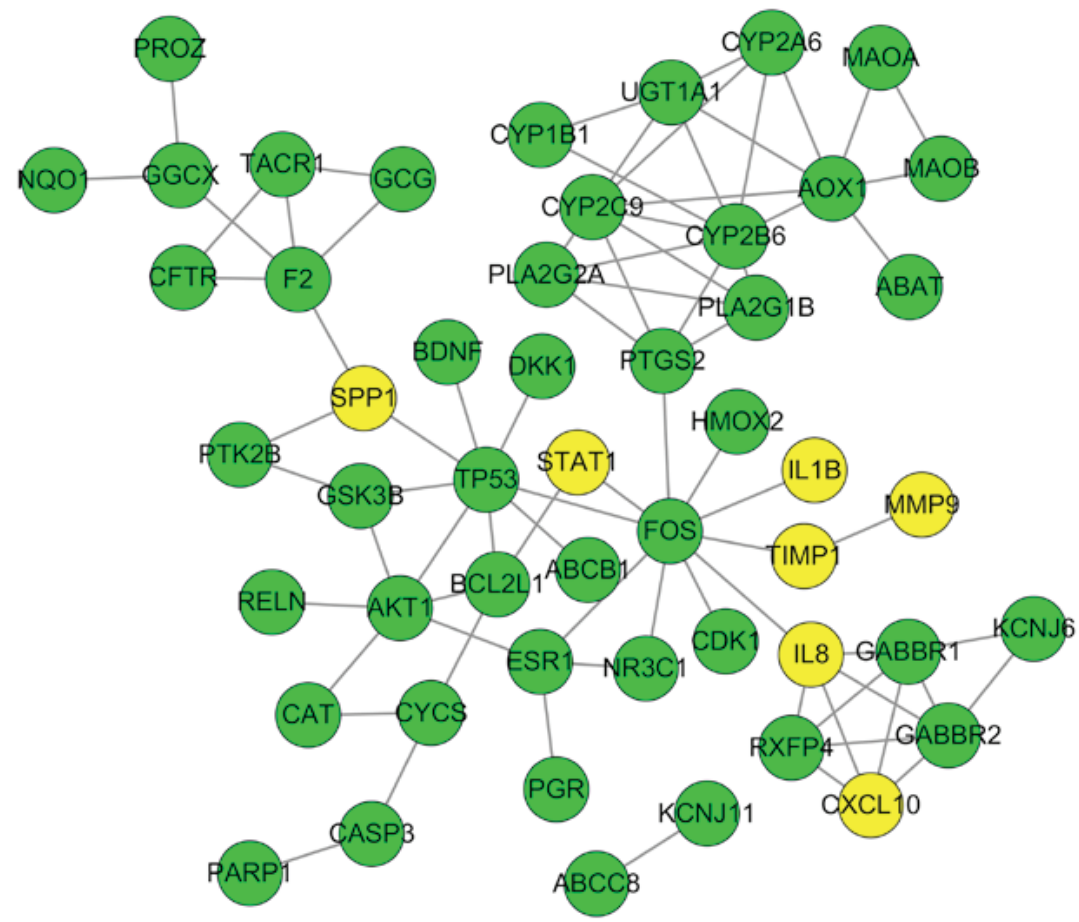

Figure 6. Protein-protein interaction network of ESCA-associated hub genes and drug-associated target genes based on STRING. All the 51 connected nodes were confirmed by Experiments and Databases of STRING. Unassociated nodes are hidden. The green circle represents target genes of predicted drug candidates, whereas the yellow circle represents the hub genes of ESCA. ESCA, esophageal carcinoma; STRING, Search Tool for the Retrieval of Interacting Genes.

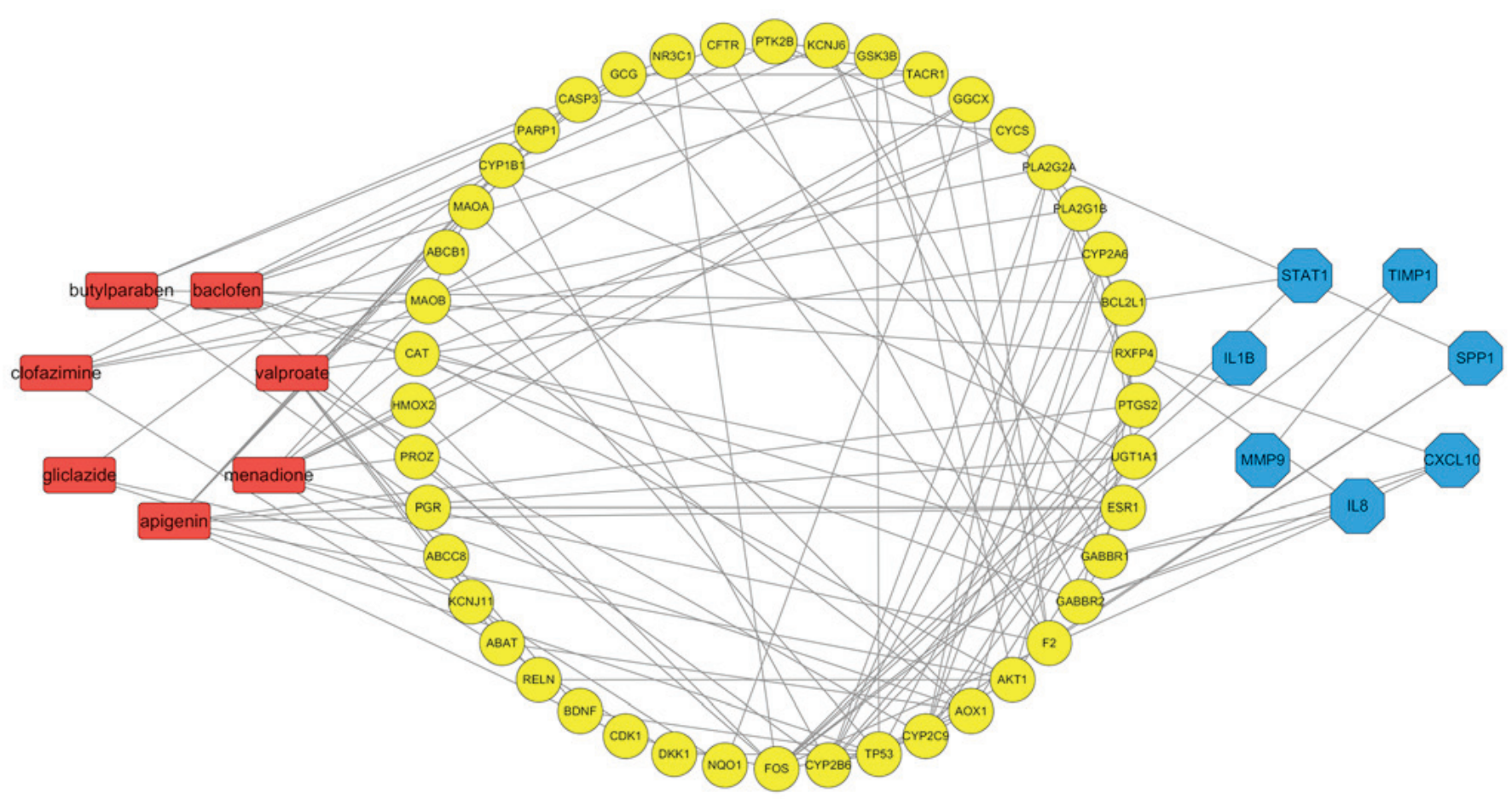

Figure 7. Network of drug candidates-target genes-ESCA-associated hub genes. Red oblongs represent predicted drug candidates; yellow circles represents $44 / 51$ selected genes, which were also target genes of goal drugs; blue polygons represent the other 7 genes also belonging to ESCA-associated hub genes. ESCA, esophageal carcinoma.

drugs in order to affect the pathways, including arachidonic acid metabolism, drug metabolism (cytochrome P450) or CCKR signaling map, as well as BP, CC or MF, particularly when regulated by the drug candidates that affect the group of 51 connected genes. Once the drug candidate-associated genes were directly associated with those ESCA hub genes, we hypothesized that they would participate in some way in ESCA pathogenesis. In such a situation, according to the results of the present study, the predicted drugs could associate with ESCA. 

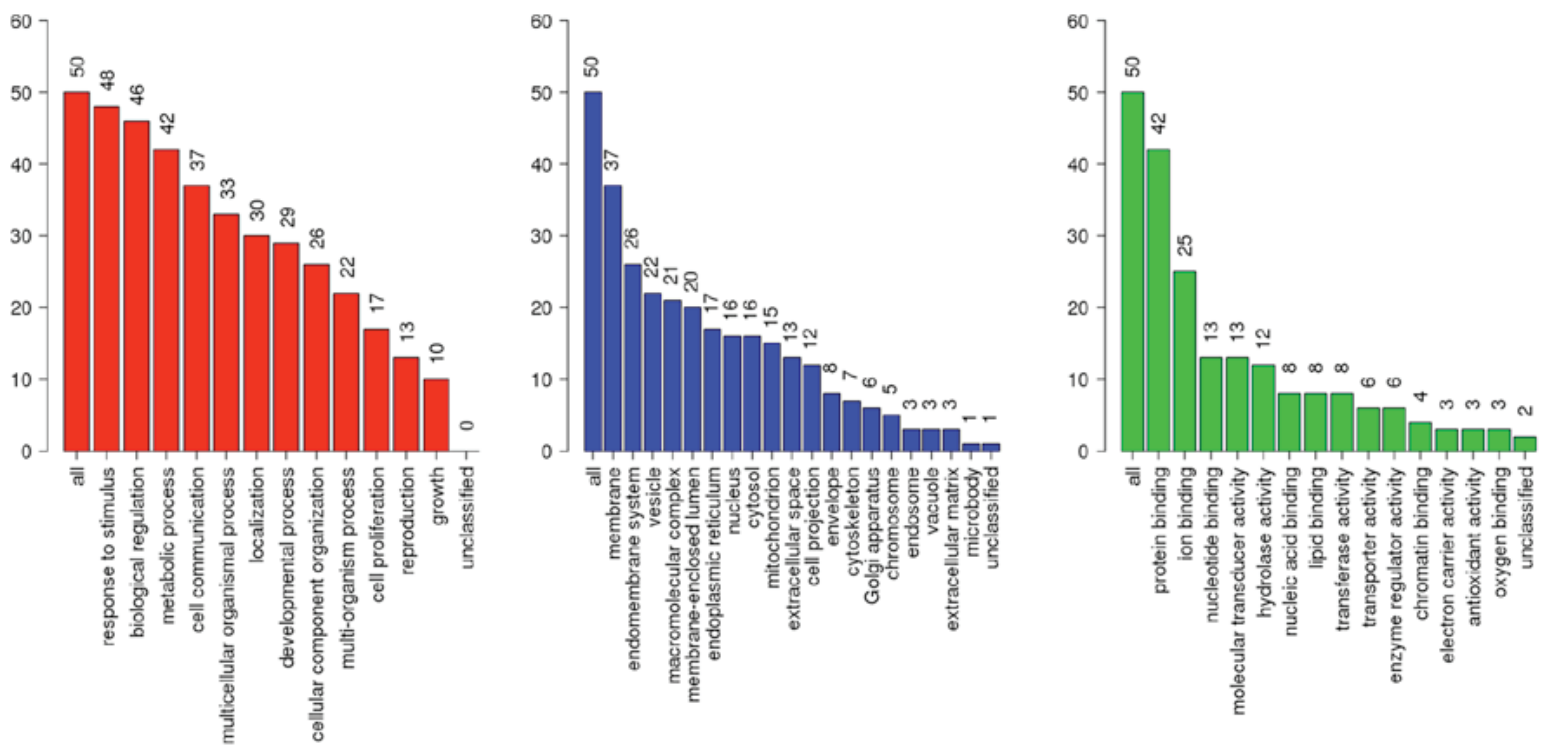

Figure 8. GO analysis of 51 genes, including 44 potential drug-associated target genes and 7 ESCA-associated hub genes. Red bars, Biological Process; blue bars, Cellular Component; green bars, Molecular Function. GO, Gene Ontology; ESCA, esophageal carcinoma.

Molecular docking between drug candidates and hub genes. Docking results are presented in Table IV, among which SPPI and CXCL1O were eliminated because of unspecified protein structures. The binding affinity between the predicted drug candidates and hub genes was evaluated by the docking scores. The score reported by the docking approach in systemsDock is a negative logarithm of experimental dissociation/inhibition constant value $\left(\mathrm{p} K_{\mathrm{d}} / \mathrm{p} K_{\mathrm{i}}\right)$, usually ranging between 0 and 10 (i.e., from weak to strong binding), allowing a straightforward indication of binding strength. According to Table IV, which lists strength by a decreasing docking score, the molecular docking pairs with a docking score of $>5.52$ were attributed to drugs including apigenin, Prestwick-685 and menadione, which overall had the top three scores in the CMAP results. The significant results were plotted by respectively selecting the top three proteins for apigenin, Prestwick-685 or menadione (Figs. 9 and 10). A flow chart of the methodology used in the present study is summarized in Fig. 11.

\section{Discussion}

In the present study, 827 DEGs of ESCA were identified, including 375 upregulated genes and 452 downregulated genes, of which the functions were analyzed. On the basis of the PPI network, 11 hub genes were extracted. To acquire potential drugs for ESCA chemotherapy, the DEGs were uploaded to CMAP and 15 drugs were selected by scores. Furthermore, $9 / 15$ drugs were identified to target 70 genes in total. However, only four gene intersections were identified in DEGs of ESCA and 70 target genes. Acetazolamide and dequalinium were also eliminated by another PPI analysis. As a result, apigenin, baclofen, Prestwick-685, menadione, butyl hydroxybenzoate, gliclazide and valproate were considered as the potential drug candidates, and the network of 7 predicted drug candidates-target genes-ESCA-associated hub genes was constructed. Furthermore, apigenin, Prestwick-685 and menadione were considered significant drug candidates by performing molecular docking.

Thus, considering the research design, three steps were taken to obtain the drug candidates for ESCA. First, full use was made of the CMAP, and the first 15 screening drugs were extracted by scores of $<-0.85$. CMAP is an online database that provides an approach to identifying the connections between small molecules, genes and diseases. It was created by the CMAP team at the Broad Institute and the resource is publicly available (portals.broadinstitute.org/cmap) (26). In CMAP, drug signatures are ordered lists of genes that are stored following the profiling of 564 drug-treated instances and identified by a computer program. Therefore, the CMAP can significantly increase the rate of drug discovery and identify novel uses for existing drugs. For example, Wang et al (38) investigated candidate drugs for hepatocellular carcinoma in the CMAP by analyzing associated subpathways. The CMAP also assisted with the identification of similar signatures of atypical meningiomas and provision of novel treatment methods (39). Additionally, Liu et al (40) used CMAP to identify some potential compounds for treating patients with B-cell chronic lymphocytic leukemia (B-CLL) on the basis of altered pathways in B-CLL. Similarly, in the present study, when 375 upregulated genes and 452 downregulated genes of ESCA were uploaded as a probe set to interrogate the CMAP, this dataset was matched with the drugs identified using a Kolmogorov-Smirnov statistical test. The drugs were sorted by their connectivity scores, which was the combination of the up score and down score. The criterion of a score of $<-0.85$ was also used to combine a high negative up score and a high positive down score, indicating that the corresponding perturbagen repressed the expression of the probe sets in the up genes list, whereas it induced the expression of the probe sets in the down genes list. Secondly, 6 drugs were eliminated when the standard of STITCH was uniformly adapted. Thirdly, a new PPI analysis was used to establish an association between target genes predicted by the second screening drugs and DEGs of 
Table IV. Predicted binding affinity between drug candidates and hub genes.

\begin{tabular}{|c|c|c|c|}
\hline Gene & PDB identifier & Test compound & Docking score $\left(\mathrm{p} K_{\mathrm{d}} / \mathrm{p} K_{\mathrm{i}}\right)$ \\
\hline STAT1 & 1BF5 & 580043: Apigenin & 7.866 \\
\hline STAT1 & 1BF5 & 2794: Prestwick-685 & 7.738 \\
\hline$M M P 9$ & $1 \mathrm{ITV}$ & 2794: Prestwick-685 & 6.768 \\
\hline TIMPI & 3MA2 & 580043: Apigenin & 6.593 \\
\hline MMP9 & $1 \mathrm{ITV}$ & 580043: Apigenin & 6.439 \\
\hline$I L 1 B$ & $2 \mathrm{NVH}$ & 580043: Apigenin & 6.422 \\
\hline STAT1 & 1BF5 & 4055: Menadione & 6.403 \\
\hline$M M P 9$ & $1 \mathrm{ITV}$ & 4055: Menadione & 5.612 \\
\hline$I L 1 B$ & $2 \mathrm{NVH}$ & 4055: Menadione & 5.592 \\
\hline IL8 & 1QE6 & 4055: Menadione & 5.431 \\
\hline$I L I B$ & $2 \mathrm{NVH}$ & 2794: Prestwick-685 & 5.417 \\
\hline$T I M P 1$ & 3MA2 & 4055: Menadione & 5.191 \\
\hline IL8 & 1QE6 & 580043: Apigenin & 5.075 \\
\hline IL8 & 1QE6 & 2794: Prestwick-685 & 4.687 \\
\hline IL8 & 1QE6 & 3475: Gliclazide & 4.617 \\
\hline$T I M P 1$ & 3MA2 & 3475: Gliclazide & 4.385 \\
\hline$T I M P 1$ & 3MA2 & 3121: Valproic acid & 4.344 \\
\hline STAT1 & 1BF5 & 3121: Valproic acid & 4.23 \\
\hline$M M P 9$ & $1 \mathrm{ITV}$ & 3121: Valproic acid & 4.131 \\
\hline$I L 1 B$ & $2 \mathrm{NVH}$ & 3121: Valproic acid & 4.092 \\
\hline IL8 & 1QE6 & 3121: Valproic acid & 4.06 \\
\hline$T I M P 1$ & 3MA2 & 2794: Prestwick-685 & 3.802 \\
\hline$T I M P 1$ & 3MA2 & 7184: Butyl hydroxybenzoate & 3.73 \\
\hline IL8 & 1QE6 & 7184: Butyl hydroxybenzoate & 3.352 \\
\hline$I L I B$ & $2 \mathrm{NVH}$ & 7184: Butyl hydroxybenzoate & 3.148 \\
\hline STAT1 & 1BF5 & 7184: Butyl hydroxybenzoate & 3.095 \\
\hline IL8 & 1QE6 & 2284: Baclofen & 2.957 \\
\hline$I L I B$ & $2 \mathrm{NVH}$ & 3475: Gliclazide & 2.894 \\
\hline$M M P 9$ & $1 \mathrm{ITV}$ & 3475: Gliclazide & 2.871 \\
\hline$M M P 9$ & $1 \mathrm{ITV}$ & 7184: Butyl hydroxybenzoate & 2.742 \\
\hline$T I M P 1$ & 3MA2 & 2284: Baclofen & 2.734 \\
\hline STAT1 & 1BF5 & 3475: Gliclazide & 2.695 \\
\hline$M M P 9$ & $1 \mathrm{ITV}$ & 2284: Baclofen & 2.571 \\
\hline$I L 1 B$ & $2 \mathrm{NVH}$ & 2284: Baclofen & 2.568 \\
\hline STAT1 & 1BF5 & 2284: Baclofen & 2.371 \\
\hline
\end{tabular}

PDB, Protein Data Bank.

ESCA previously obtained from TCGA and GTEx databases, of which the indicators were artificially set with 'experiments' and 'database' for a higher reliability. Therefore, those drugs corresponding to the certified associated genes were finally retained as potential drug candidates for ESCA.

The retrieval of relevant literature on drug candidates was required to further understand their research status and clinical application, as well as support the prediction. Among the 7 predicted drugs, apigenin is a natural product that is present in a number of plants. It was confirmed to have an anticancer effect on different types of cancer (41-45). Apigenin was once reported to induce apoptosis in ESCA cells through destruction of the membrane structure (46).
As Yan et al (47) summarized, apigenin may be an adjuvant chemotherapeutic agent for cancer therapy by modulating the phosphoinositide 3-kinase/protein kinase B, mitogen-activated protein kinase/extracellular-signal-regulated kinase, Janus kinase/signal transducer and activator of transcription, nuclear factor- $\kappa \mathrm{B}(\mathrm{NF}-\kappa \mathrm{B})$, and $\mathrm{Wnt} / \beta$-catenin signaling pathways. In addition, it was also reported that apigenin may have a further function in cancer chemoprevention via the induction of apoptosis and autophagy (48).

Baclofen is commonly used for treating spastic movement disease $(49,50)$. However, baclofen may help to inhibit hiccups following the insertion of a stent for ESCC, according to a case report (51), and it was suggested that it may be a useful 

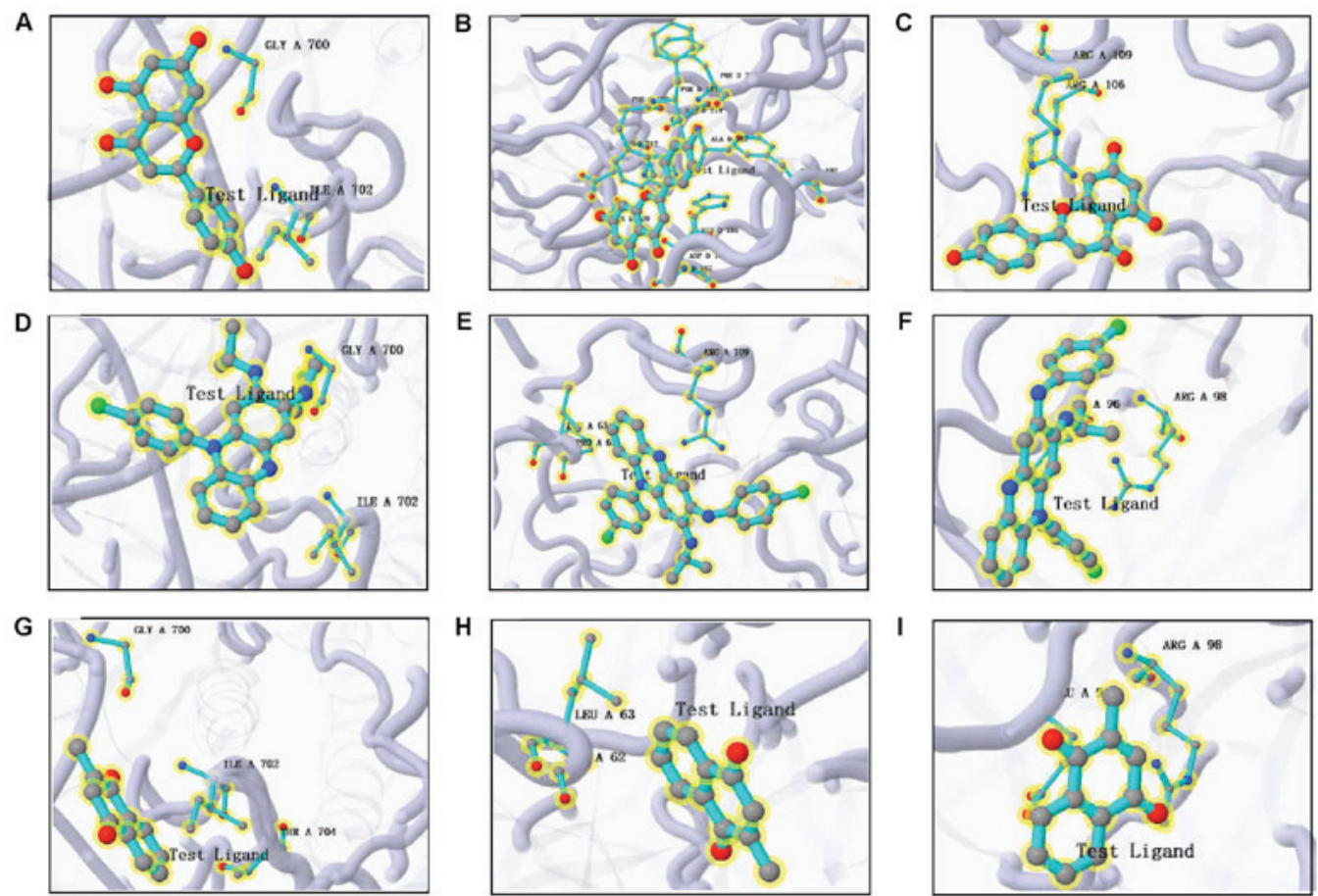

Figure 9. Three-dimensional structures of the significant test ligand (residue)-protein based on systemDock. (A) Apigenin-STAT1; (B) apigenin-tissue inhibitor of metalloproteinase 1; (C) apigenin-MMP9; (D) Prestwick-685-STAT1; (E) Prestwick-685-MMP9; (F) Prestwick-685-IL-1B; (G) menadione-STAT1; (H) menadione-MMP9; (I) menadione-IL-1B. STAT1, signal transducer and activator of transcription 1; MMP9, matrix metalloproteinase 9; IL-1B, interleukin 1B.

A

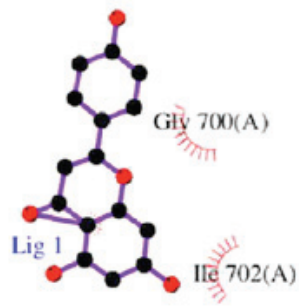

D
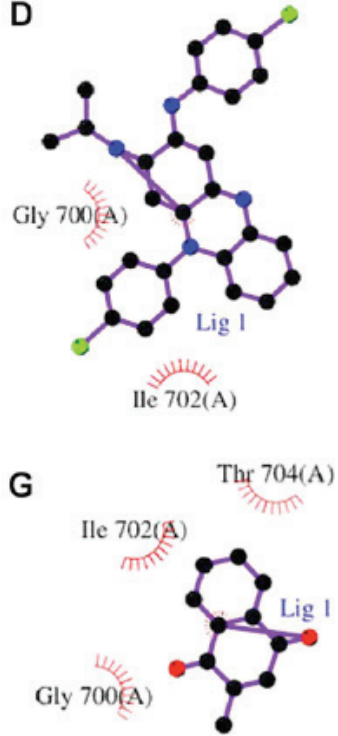

B

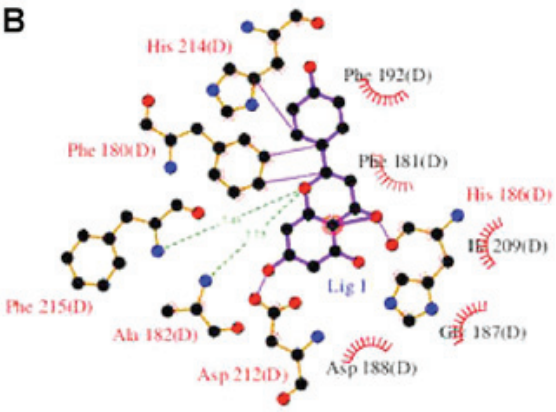

E

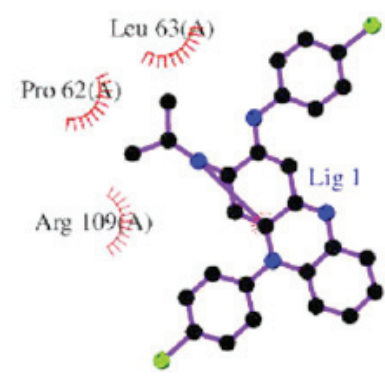

H

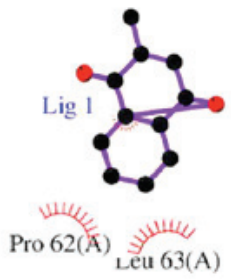

C

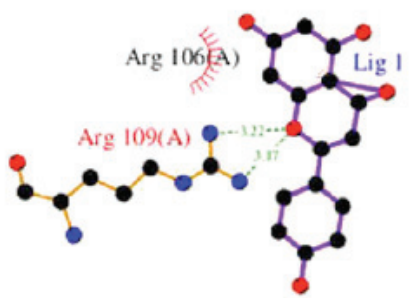

$\mathbf{F}$
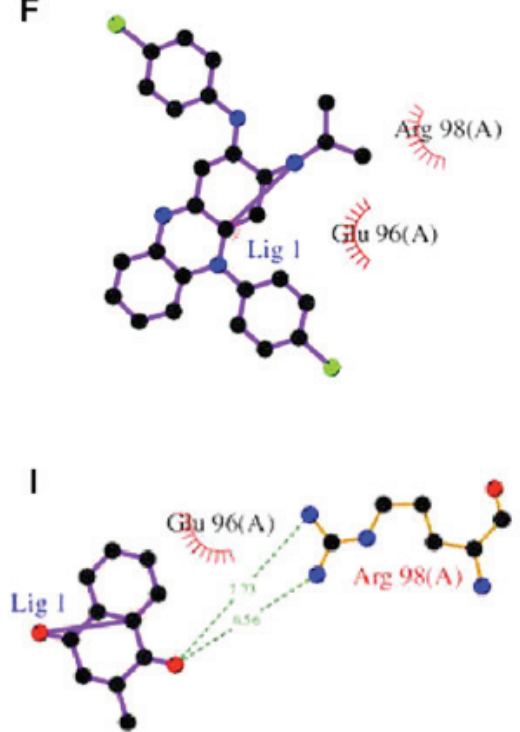

Figure 10. Two-dimensional structures of the significant test ligand (residue)-protein based on systemDock. (A) Apigenin-STAT1; (B) apigenin-tissue inhibitor of metalloproteinase 1; (C) apigenin-MMP9; (D) Prestwick-685-STAT1; (E) Prestwick-685-MMP9; (F) Prestwick-685-IL-1B; (G) menadione-STAT1; (H) menadione-MMP9; (I) menadione-IL-1B. STAT1, signal transducer and activator of transcription 1; MMP9, matrix metalloproteinase 9; IL-1B, interleukin 1B. 


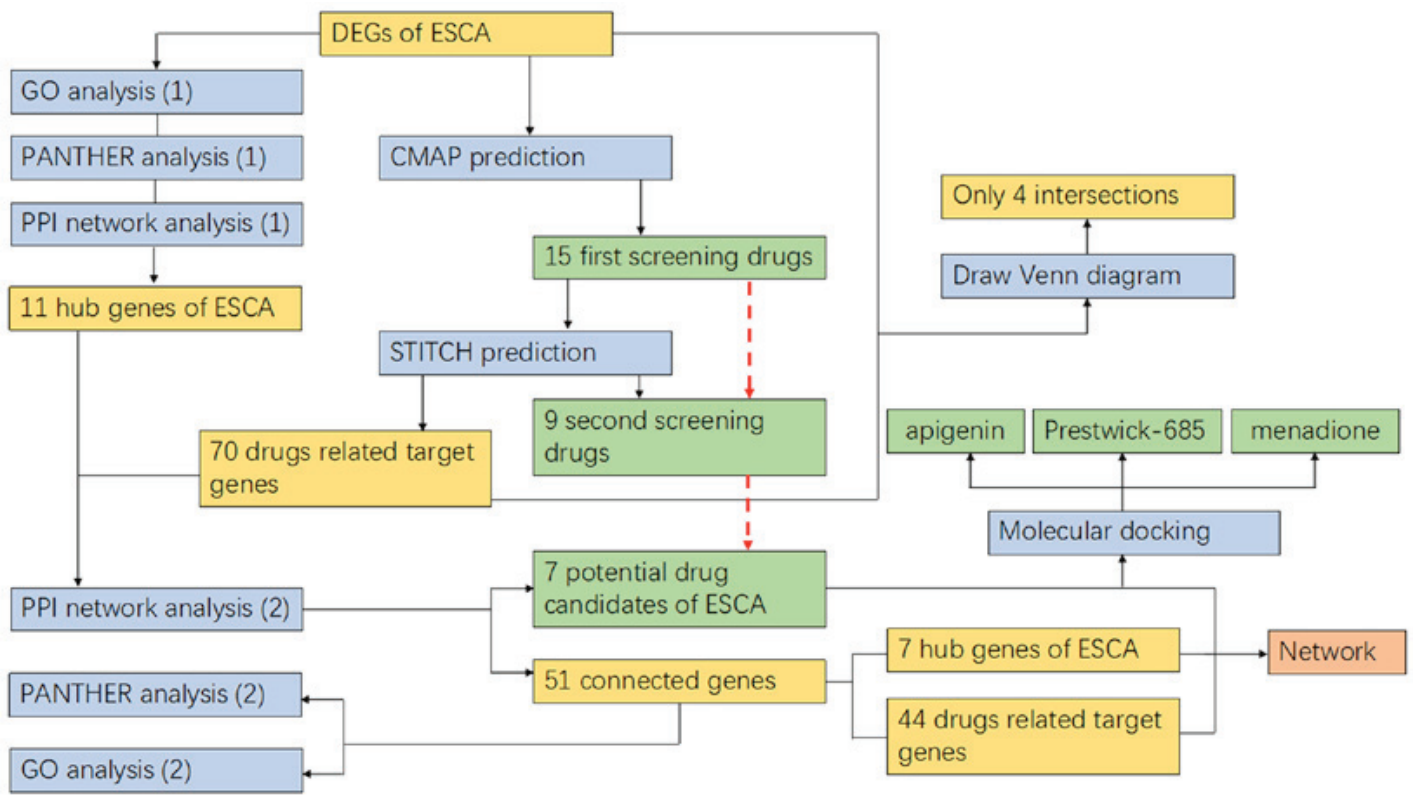

Figure 11. Flow chart of the methodology used. The blue boxes represent the process, the green boxes represent the screening drugs, and the yellow boxes represent the other results for corresponding processes. The red dotted line indicates the drug screening process.

adjuvant analgesic for decreasing cancer pain (52). Whether baclofen has any anticancer effects or not remains unknown owing to a lack of relevant research. Prestwick-685, also named clofazimine in PubChem, was identified to be associated with breast cancer (53) and lung cancer (54). Recently, Durusu et al (54) provided novel evidence for the anticancer effect of clofazimine, which implies that clofazimine also requires further investigation regarding cancer treatment. Compared with clofazimine, it appears that menadione, which is also known as vitamin $\mathrm{K} 3$, has attracted more attention from the perspective of cancer treatment. Menadione has been identified to exhibit significant therapeutic benefits in the treatment of gastric cancer (55), prostate cancer (56), oral cancer (57) and breast cancer (58). Furthermore, the latest research indicated that menadione may increase anticancer activity by combining ROS-generating agents (59), but how it works in ESCA treatment requires further investigation. Butyl hydroxybenzoate, also called butylparaben, is often used as a flavoring additive in food. However, it is reported to participate in a non-genomic mechanism of activation of G-protein-coupled receptor 30 in cancerous and non-cancerous breast cell lines through activation of the extracellular-signal-regulated kinase $1 / 2$ pathway; further research into the carcinogenic action is required (60). Gliclazide is generally used for treating diabetes $(61,62)$, but its anticancer effect has seldom been explored $(63,64)$. Lastly, valproate has proved to be a potent tool in treating cancer via enhancing doxorubicin cytotoxicity and the efficacy of vinorelbine-cisplatin-based chemoradiation, according to recent studies (65-68). In summary, on the basis of the bioinformatics prediction of the present study and aforementioned studies, apigenin, menadione and valproate are hypothesized to have an increased possibility of becoming the chemotherapeutics for ESCA.

Although a number of the predicted drug candidates for ESCA have not exhibited specific anticancer effects previously, drug repurposing was investigated via efficient bioinformatics analysis and a structure exploration, which means that the excavation of novel drug candidates in the present study was primarily based on the drug repurposing. In particular, the three-step filtering of drug candidates for ESCA executed the drug repurposing simultaneously. In the present study, ESCA was characterized by its DEGs, and the potential effects of drugs were characterized by their target genes. To the extent of searching drugs, the application of extracted DEGs was primarily utilized for screening drugs via CMAP and posteriorly established linkages with drug-associated target genes, which consequently made a connection between ESCA and drugs. In line with this process, the two-time functional analysis of two gene groups, of which one group contains the 827 extracted DEGs of ESCA and the other group contained 51 genes that displayed in the drug candidates-target genes-ESCA-associated hub genes network, explained the underlying pathogenesis of ESCA and predicted the potential influence of drugs. Results of pathway analysis coincided with the arachidonic acid metabolism and drug metabolism (cytochrome P450), on the basis of KEGG analysis, as well as with the CCKR signaling map, on the basis of PANTHER analysis. According to GO analysis, the similar results indicated that, among the drug-associated target genes, 66 unremarkable genes in ESCA, particularly those in the group of 51 connected genes, may be regulated by several drugs to affect the $\mathrm{BP}, \mathrm{CC}$ or $\mathrm{MF}$ and were associated with those hub genes of ESCA, which, as a result, may influence ESCA pathogenesis.

In addition to the bioinformatics database analysis, drug repurposing was also investigated via structure exploration. Docking was used to screen the proteins and identify potential targets for a query ligand (69). Molecular docking is one of the key steps for proper computational reconstruction of actual ligand-receptor or protein-protein interactions, and thus is relevant to drug design and ligands discovery (70-74). In the present study, the binding affinity between drug molecules and 
proteins was determined. Apigenin, Prestwick-685 and menadione were predicted to be potential drugs that may affect the target genes, together with ESCA-associated hub genes that influence pathogenesis. Higher linking affinity in this step to hub genes in the network confirmed apigenin, Prestwick-685 and menadione to be significant drug candidates, as well as confirmed the CMAP results. Therefore, in taking full advantage of databases and molecule docking, drug repurposing of Prestwick-685 and menadione was achieved, as apigenin has been reported to induce apoptosis in ESCA cells (46). Thus, Prestwick-685 and menadione were considered to be significant novel drug candidates.

Furthermore, the biological significance of five vital hub genes, including STAT1, matrix MMP9, TIMP1, IL1B and $I L 8$, for ESCA can be explained. According to previous studies (75), STATl was reported to be a tumor suppressor in ESCC by downregulating the activity of NF- $\mathrm{kB}$ and STAT3, and it was associated with the substantial downregulation of several pro-survival proteins such as B-cell lymphoma (Bcl)-2, Bcl-extra-large and survivin, as well as modulation of two G1 cell-cycle-regulatory proteins, $\mathrm{p} 21^{\text {wafl }}$ and cyclin D1 (76). $M M P 9$ was also demonstrated to be a prognostic factor in ESCA (77), and MMP9 upregulated by protein tyrosine kinase 7 through activation of activator protein 1 and NF- $\kappa B$ could increase the invasive properties of ESCC cells (78). Studies have identified that high serum levels of TIMPI were associated with tumor progression and unfavorable prognosis in patients with ESCA $(79,80)$. For $I L 1 B$, it was only reported that the rs $16944 \mathrm{G}>$ A polymorphism may contribute to ESCC susceptibility (81). For $I L 8$, it is significantly upregulated during esophageal carcinogenesis, and the IL-8/CXC chemokine receptor 2 signaling pathway is a potential therapeutic target in EAC (82). To summarize, the significant biological functions of STATI, MMP9, TIMPI, ILIB and IL8 in ESCA provided solid reasons for their being therapeutic targets for patients with ESCA, for which the novel drug candidates may serve certain positive functions in the molecular docking, as predicted.

The present study had certain limitations. The results relied heavily on the bioinformatics database and thus were significantly influenced by the refresh rate of data. Furthermore, drug experiments were not performed, meaning that the predicted drugs may lack effective verification. Despite the limitations, however, full use was made of the DEGs of ESCA in CMAP, STITCH, PPI network and molecular docking, as well as functional analysis including KEGG, PANTHER and GO analysis, to screen for novel drug candidates for ESCA and have confirmed their potential therapeutic effect at a bioinformatics level. Thus, to a certain extent, the present study may provide a reference for the chemotherapy of ESCA, in its molecular biology and methodology, which similar studies have not yet reported. Furthermore, the results require further investigation, as well as in vivo studies.

\section{Acknowledgements}

The authors thank Dr Xia Yang (Department of Pathology, First Affiliated Hospital of Guangxi Medical University, Nanning, China), for providing valuable suggestions on writing the original manuscript.

\section{Funding}

The present study was supported by the Project of Future Academic Star in Guangxi Medical University, China (grant no. WLXSZX18004) and the Guangxi Zhuang Autonomous Region University Student Innovative Plan, China (grant no. 2018049).

\section{Availability of data and materials}

The datasets generated and analyzed during the current study are available in TCGA database (cancergenome.nih.gov), GTEx database (gtexportal.org/home) and CMAP database (portals.broadinstitute.org/cmap).

\section{Authors' contributions}

The study was conceived and designed by YTC, JYX, QS and WJM. YTC, JYX and QS participated in the data mining. YTC analyzed and interpreted data and drafted the manuscript. JYX participated in drafting the manuscript. All authors read and approved the final manuscript.

\section{Ethics approval and consent to participate}

Not applicable.

\section{Patient consent for publication}

Not applicable.

\section{Competing interests}

The authors declare that they have no competing interests.

\section{References}

1. MaK, Cao B and Guo M: The detective, prognostic, and predictive value of DNA methylation in human esophageal squamous cell carcinoma. Clin Epigenetics 8: 43, 2016.

2. Siegel RL, Miller KD and Jemal A: Cancer statistics, 2018. CA Cancer J Clin 68: 7-30, 2018.

3. Erkizan HV, Johnson K, Ghimbovschi S, Karkera D, Trachiotis G, Adib H, Hoffman EP and Wadleigh RG: African-American esophageal squamous cell carcinoma expression profile reveals dysregulation of stress response and detox networks. BMC Cancer 17: 426, 2017.

4. Jiang S, Zhang Q, Su Y and Pan L: Network-based differential analysis to identify molecular features of tumorigenesis for esophageal squamous carcinoma. Molecules 23: 23, 2018.

5. Yang XX, Ma M, Sang MX, Wang XX, Song H, Liu ZK and Zhu SC: Radiosensitization of esophageal carcinoma cells by knockdown of RNF2 expression. Int J Oncol 48: 1985-1996, 2016.

6. Ma Z, Cai H and Cui Y: Progress in the treatment of esophageal neuroendocrine carcinoma. Tumour Biol 39: 1010428317711313, 2017.

7. Vellayappan BA, Soon YY, Ku GY, Leong CN, Lu JJ and Tey JC: Chemoradiotherapy versus chemoradiotherapy plus surgery for esophageal cancer. Cochrane Database Syst Rev 8: CD010511, 2017.

8. Chen GZ, Zhu HC, Dai WS, Zeng XN, Luo JH and Sun XC: The mechanisms of radioresistance in esophageal squamous cell carcinoma and current strategies in radiosensitivity. J Thorac Dis 9: 849-859, 2017.

9. Recio-Boiles A and Babiker HM: Cancer, Esophageal. In: StatPearls [Internet]. StatPearls Publishing, Treasure Island, FL, 2018. 
10. Sasaki Y and Kato K: Chemoradiotherapy for esophageal squamous cell cancer. Jpn J Clin Oncol 46: 805-810, 2016.

11. Harada K, Mizrak Kaya D, Baba H and Ajani JA: Immune checkpoint blockade therapy for esophageal squamous cell carcinoma. J Thorac Dis 10: 699-702, 2018.

12. Cai Z, Lv H, Cao W, Zhou C, Liu Q, Li H and Zhou F: Targeting strategies of adenovirus mediated gene therapy and virotherapy for prostate cancer (Review). Mol Med Rep 16: 6443-6458, 2017.

13. Grisham RN and Iyer G: Low-grade serous ovarian cancer: Current treatment paradigms and future directions. Curr Treat Options Oncol 19: 54, 2018.

14. Le Grazie M, Biagini MR, Tarocchi M, Polvani S and Galli A: Chemotherapy for hepatocellular carcinoma: The present and the future. World J Hepatol 9: 907-920, 2017.

15. Mayank and Jaitak V: Drug target strategies in breast cancer treatment: Recent developments. Anticancer Agents Med Chem 14: 1414-1427, 2014.

16. Michels S and Wolf J: Stratified treatment in lung cancer. Oncol Res Treat 39: 760-766, 2016.

17. Jia Y, Xiao Z, Gongsun X, Xin Z, Shang B, Chen G, Wang Z and Jiang W: CEP55 promotes the proliferation, migration and invasion of esophageal squamous cell carcinoma via the PI3K/Akt pathway. OncoTargets Ther 11: 4221-4232, 2018.

18. Niyaz M, Abdurahman A, Turghun A and Awut I: CEP3 and CEP17 DNA probe potential in the genetic diagnosis and prognostic prediction of esophageal squamous cell cancer. Exp Ther Med 11: 1375-1380, 2016.

19. Wang H, Zhou Y, Liu Q, Xu J and Ma Y: Prognostic value of SOX2, Cyclin D1, P53, and ki-67 in patients with esophageal squamous cell carcinoma. OncoTargets Ther 11: 5171-5181, 2018

20. Lin S, Liu K, Zhang Y, Jiang M, Lu R, Folts CJ, Gao X, Noble MD, Zhao T, Zhou Z, et al: Pharmacological targeting of p38 MAP-Kinase 6 (MAP2K6) inhibits the growth of esophageal adenocarcinoma. Cell Signal 51: 222-232, 2018.

21. MacGregor TP, Carter R, Gillies RS, Findlay JM, Kartsonaki C, Castro-Giner F, Sahgal N, Wang LM, Chetty R, Maynard ND, et al: Translational study identifies XPF and MUS81 as predictive biomarkers for oxaliplatin-based peri-operative chemotherapy in patients with esophageal adenocarcinoma. Sci Rep 8: 7265, 2018

22. Chang ZW, Jia YX, Zhang WJ, Song LJ, Gao M, Li MJ, Zhao RH, Li J, Zhong YL, Sun QZ, et al: LncRNA-TUSC7/miR-224 affected chemotherapy resistance of esophageal squamous cell carcinoma by competitively regulating DESC1. J Exp Clin Cancer Res 37: 56, 2018.

23. Liu B, Wang C, Chen P, Cheng B and Cheng Y: RACKI induces chemotherapy resistance in esophageal carcinoma by upregulating the PI3K/AKT pathway and $\mathrm{Bcl}-2$ expression. OncoTargets Ther 11: 211-220, 2018.

24. Yu X, Li W, Xia Z, Xie L, Ma X, Liang Q, Liu L, Wang J, Zhou X Yang Y, et al: Targeting MCL-1 sensitizes human esophageal squamous cell carcinoma cells to cisplatin-induced apoptosis. BMC Cancer 17: 449, 2017.

25. Pang Y, Liu J, Li X, Zhang Y, Zhang B, Zhang J, Du N, Xu C, Liang R, Ren $\mathrm{H}$, et al: Nano Let $7 \mathrm{~b}$ sensitization of eliminating esophageal cancer stem like cells is dependent on blockade of Wnt activation of symmetric division. Int J Oncol 51: 1077-1088, 2017.

26. Lamb J, Crawford ED, Peck D, Modell JW, Blat IC, Wrobel MJ, Lerner J, Brunet JP, Subramanian A, Ross KN, et al: The Connectivity Map: Using gene-expression signatures to connect small molecules, genes, and disease. Science 313: 1929-1935, 2006.

27. Lin P, Xiong DD, Dang YW, Yang H, He Y, Wen DY, Qin XG and Chen G: The anticipating value of PLK1 for diagnosis, progress and prognosis and its prospective mechanism in gastric cancer: A comprehensive investigation based on high-throughput data and immunohistochemical validation. Oncotarget 8: 92497-92521, 2017.

28. Dang YW, Lin P, Liu LM, He RQ, Zhang LJ, Peng ZG, Li XJ and Chen G: In silico analysis of the potential mechanism of telocinobufagin on breast cancer MCF-7 cells. Pathol Res Pract 214: 631-643, 2018

29. He RQ, Yang X, Liang L, Chen G and Ma J: MicroRNA-124-3p expression and its prospective functional pathways in hepatocellular carcinoma: A quantitative polymerase chain reaction, gene expression omnibus and bioinformatics study. Oncol Lett 15: 5517-5532, 2018.

30. Li HM, Yang H, Wen DY, Luo YH, Liang CY, Pan DH, Ma W, Chen G, He Y and Chen JQ: Overexpression of LncRNA HOTAIR is associated with poor prognosis in thyroid carcinoma: A study based on TCGA and GEO data. Horm Metab Res 49: 388-399, 2017.
31. Shannon P, Markiel A, Ozier O, Baliga NS, Wang JT, Ramage D, Amin N, Schwikowski B and Ideker T: Cytoscape: A software environment for integrated models of biomolecular interaction networks. Genome Res 13: 2498-2504, 2003

32. Gao L, Li SH, Tian YX, Zhu QQ, Chen G, Pang YY and Hu XH: Role of downregulated miR-133a-3p expression in bladder cancer: A bioinformatics study. OncoTargets Ther 10: 3667-3683, 2017.

33. He RQ, Wu PR, Xiang XL, Yang X, Liang HW, Qiu XH, Yang LH, Peng ZG and Chen G: Downregulated miR-23b-3p expression acts as a predictor of hepatocellular carcinoma progression: A study based on public data and RT-qPCR verification. Int J Mol Med 41: 2813-2831, 2018.

34. Liang L, Wei DM, Li JJ, Luo DZ, Chen G, Dang YW and Cai XY: Prognostic microRNAs and their potential molecular mechanism in pancreatic cancer: A study based on The Cancer Genome Atlas and bioinformatics investigation. Mol Med Rep 17: 939-951, 2018.

35. Pathan M, Keerthikumar S, Ang CS, Gangoda L, Quek CY, Williamson NA, Mouradov D, Sieber OM, Simpson RJ, Salim A, et al: FunRich: An open access standalone functional enrichment and interaction network analysis tool. Proteomics 15: 2597-2601, 2015.

36. Hsin KY, Ghosh $\mathrm{S}$ and Kitano $\mathrm{H}$ : Combining machine learning systems and multiple docking simulation packages to improve docking prediction reliability for network pharmacology. PLoS One 8: e83922, 2013.

37. Hsin KY, Matsuoka Y, Asai Y, Kamiyoshi K, Watanabe T, Kawaoka Y and Kitano H: systemsDock: A web server for network pharmacology-based prediction and analysis. Nucleic Acids Res 44 (W1): W507-13, 2016.

38. Wang J, Li M, Wang Y and Liu X: Integrating subpathway analysis to identify candidate agents for hepatocellular carcinoma. OncoTargets Ther 9: 1221-1230, 2016.

39. Zador Z, King AT and Geifman N: New drug candidates for treatment of atypical meningiomas: An integrated approach using gene expression signatures for drug repurposing. PLoS One 13: e0194701, 2018.

40. Liu G, Hu X, Gao L and Feng Z: Personalized drug analysis in B cell chronic lymphocytic leukemia patients. Med Sci Monit 23: 2159-2167, 2017.

41. Nelson N, Szekeres K, Iclozan C, Rivera IO, McGill A, Johnson G, Nwogu O and Ghansah T: Apigenin: Selective CK2 inhibitor increases Ikaros expression and improves T cell homeostasis and function in murine pancreatic cancer. PLoS One 12: e0170197, 2017.

42. Pal MK, Jaiswar SP, Dwivedi A, Goyal S, Dwivedi VN, Pathak AK, Kumar V, Sankhwar PL and Ray RS: Synergistic effect of graphene oxide coated nanotised apigenin with paclitaxel (GO-NA/PTX): A ROS dependent mitochondrial mediated apoptosis in ovarian cancer. Anticancer Agents Med Chem 17: 1721-1732, 2017.

43. Shan S, Shi J, Yang P, Jia B, Wu H, Zhang X and Li Z: Apigenin restrains colon cancer cell proliferation via targeted blocking of pyruvate kinase M2-dependent glycolysis. J Agric Food Chem 65: 8136-8144, 2017

44. Vrhovac Madunić I, Madunić J, Antunović M, Paradžik M, Garaj-Vrhovac V, Breljak D, Marijanović I and Gajski G: Apigenin, a dietary flavonoid, induces apoptosis, DNA damage, and oxidative stress in human breast cancer MCF-7 and MDA MB-231 cells. Naunyn Schmiedebergs Arch Pharmacol 391: 537-550, 2018.

45. Zhou Z, Tang M, Liu Y, Zhang Z, Lu R and Lu J: Apigenin inhibits cell proliferation, migration, and invasion by targeting Akt in the A549 human lung cancer cell line. Anticancer Drugs 28: 446-456, 2017.

46. Zhu H, Jin H, Pi J, Bai H, Yang F, Wu C, Jiang J and Cai J: Apigenin induced apoptosis in esophageal carcinoma cells by destruction membrane structures. Scanning 38: 322-328, 2016.

47. Yan X, Qi M, Li P, Zhan Y and Shao H: Apigenin in cancer therapy: Anti-cancer effects and mechanisms of action. Cell Biosci 7: 50, 2017.

48. Sung B, Chung HY and Kim ND: Role of apigenin in cancer prevention via the induction of apoptosis and autophagy. J Cancer Prev 21: 216-226, 2016.

49. Pérez-Arredondo A, Cázares-Ramírez E, Carrillo-Mora P, Martínez-Vargas M,Cárdenas-Rodríguez N, Coballase-UrrutiaE, Alemón-Medina R, Sampieri A III, Navarro L and Carmona-Aparicio L: Baclofen in the therapeutic of sequele of traumatic brain injury: Spasticity. Clin Neuropharmacol 39: 311-319, 2016. 
50. Ertzgaard P, Campo $C$ and Calabrese A: Efficacy and safety of oral baclofen in the management of spasticity: A rationale for intrathecal baclofen. J Rehabil Med 49: 193-203, 2017.

51. Sharma V, De A, Lamoria S and Lamba BM: Baclofen-responsive hiccups after esophageal stenting for malignancy-related dysphagia. Proc Bayl Univ Med Cent 29: 150, 2016.

52. Yomiya K, Matsuo N, Tomiyasu S, Yoshimoto T, Tamaki T, Suzuki T and Matoba M: Baclofen as an adjuvant analgesic for cancer pain. Am J Hosp Palliat Care 26: 112-118, 2009.

53. Koval AV, Vlasov P, Shichkova P, Khunderyakova S, Markov Y, Panchenko J, Volodina A, Kondrashov FA and Katanaev VL: Anti-leprosy drug clofazimine inhibits growth of triple-negative breast cancer cells via inhibition of canonical Wnt signaling. Biochem Pharmacol 87: 571-578, 2014.

54. Durusu IZ, Hüsnügil HH, Ataş H, Biber A, Gerekçi S, Güleç EA and Özen C: Anti-cancer effect of clofazimine as a single agent and in combination with cisplatin on U266 multiple myeloma cell line. Leuk Res 55: 33-40, 2017.

55. Lee MH, Cho Y, Kim DH, Woo HJ, Yang JY, Kwon HJ, Yeon MJ, Park M, Kim SH, Moon C, et al: Menadione induces G2/M arrest in gastric cancer cells by down-regulation of CDC25C and proteasome mediated degradation of CDK1 and cyclin B1. Am J Transl Res 8: 5246-5255, 2016

56. Prasad CV, Nayak VL, Ramakrishna S and Mallavadhani UV: Novel menadione hybrids: Synthesis, anticancer activity, and cell-based studies. Chem Biol Drug Des 91: 220-233, 2018.

57. Delwar ZM, Siden A, Cruz MH and Yakisich JS Menadione: Sodium orthovanadate combination eliminates and inhibits migration of detached cancer cells. ISRN Pharmacol 2012: 307102, 2012.

58. Yamada A, Osada S, Tanahashi T, Matsui S, Sasaki Y, Tanaka Y, Okumura N, Matsuhashi N, Takahashi T, Yamaguchi K, et al: Novel therapy for locally advanced triple-negative breast cancer. Int J Oncol 47: 1266-1272, 2015.

59. Teixeira J, Amorim R, Santos K, Soares P, Datta S, Cortopassi GA Serafim TL, Sardão VA, Garrido J, Borges F, et al: Disruption of mitochondrial function as mechanism for anti-cancer activity of a novel mitochondriotropic menadione derivative. Toxicology 393 $123-139,2018$

60. Wróbel AM and Gregoraszczuk EL: Action of methyl-, propyland butylparaben on GPR30 gene and protein expression, cAMP levels and activation of ERK1/2 and PI3K/Akt signaling pathways in MCF-7 breast cancer cells and MCF-10A non-transformed breast epithelial cells. Toxicol Lett 238: 110-116, 2015.

61. Leiter LA, Shestakova MV and Satman I: Effectiveness of gliclazide MR $60 \mathrm{mg}$ in the management of type 2 diabetes: Analyses from the EASYDia trial. Diabetol Metab Syndr 10: 30, 2018.

62. Mikov M, Danic M, Pavlovic N, Stanimirov B, Goločorbin-Kon S, Stankov K and Al-Salami H: Potential applications of gliclazide in treating type 1 diabetes mellitus: Formulation with bile acids and probiotics. Eur J Drug Metab Pharmacokinet 43: 269-280, 2018.

63. Sliwinska A, Rogalska A, Szwed M, Kasznicki J, Jozwiak Z and Drzewoski J: Gliclazide may have an antiapoptotic effect related to its antioxidant properties in human normal and cancer cells. Mol Biol Rep 39: 5253-5267, 2012.

64. Sliwinska A, Sliwinski T, Kasznicki J and Drzewoski J: Effect of gliclazide on nucleotide excision repair (NER) and non-homologous DNA end joining (NHEJ) in normal and cancer cells. J Physiol Pharmacol 61: 347-353, 2010.

65. Caponigro F, Di Gennaro E, Ionna F, Longo F, Aversa C, Pavone E, Maglione MG, Di Marzo M, Muto P, Cavalcanti E, et al: Phase II clinical study of valproic acid plus cisplatin and cetuximab in recurrent and/or metastatic squamous cell carcinoma of Head and Neck-V-CHANCE trial. BMC Cancer 16: 918, 2016.

66. Scialdone A, Hasni MS, Damm JK, Lennartsson A, Gullberg U and Drott K: The HDAC inhibitor valproate induces a bivalent status of the CD20 promoter in CLL patients suggesting distinct epigenetic regulation of CD20 expression in CLL in vivo. Oncotarget 8: 37409-37422, 2017.
67. Sha S, Zhai Y, Lin C, Wang H, Chang Q, Song S, Ren M and Liu G: A combination of valproic acid sodium salt, CHIR99021, E-616452, tranylcypromine, and 3-Deazaneplanocin A causes stem cell-like characteristics in cancer cells. Oncotarget 8: 53302-53312, 2017

68. Wei M, Mao S, Lu G, Li L, Lan X, Huang Z, Chen Y, Zhao M, Zhao Y and Xia Q: Valproic acid sensitizes metformin-resistant human renal cell carcinoma cells by upregulating $\mathrm{H} 3$ acetylation and EMT reversal. BMC Cancer 18: 434, 2018.

69. Xu X, Huang M and Zou X: Docking-based inverse virtual screening: Methods, applications, and challenges. Biophys Rep 4: 1-16, 2018.

70. Abdolmaleki A, Ghasemi JB and Ghasemi F: Computer aided drug design for multi-target drug design: SAR/QSAR, molecular docking and pharmacophore methods. Curr Drug Targets 18: 556-575, 2017.

71. Bartuzi D, Kaczor AA, Targowska-Duda KM and Matosiuk D: Recent advances and applications of molecular docking to G protein-coupled receptors. Molecules 22: 22, 2017

72. de Ruyck J, Brysbaert G, Blossey R and Lensink MF: Molecular docking as a popular tool in drug design, an in silico travel. Adv Appl Bioinform Chem 9: 1-11, 2016.

73. Rosano C, Ponassi M, Santolla MF, Pisano A, Felli L, Vivacqua A, Maggiolini M and Lappano R: Macromolecular modelling and docking simulations for the discovery of selective GPER ligands. AAPS J 18: 41-46, 2016.

74. Scotti L, Mendonca Junior FJ, Ishiki HM, Ribeiro FF, Singla RK, Barbosa Filho JM, Da Silva MS and Scotti MT: Docking studies for multi-target drugs. Curr Drug Targets 18: 592-604, 2017.

75. Zhang Y, Molavi O, Su M and Lai R: The clinical and biological significance of STAT1 in esophageal squamous cell carcinoma. BMC Cancer 14: 791, 2014.

76. Zhang Y,Zhang Y, Yun H, Lai R and Su M: Correlation of STAT1 with apoptosis and cell-cycle markers in esophageal squamous cell carcinoma. PLoS One 9: e113928, 2014.

77. Klimczak-Bitner AA, Kordek R, Bitner J, Musiał J and Szemraj J: Expression of MMP9, SERPINE1 and miR-134 as prognostic factors in esophageal cancer. Oncol Lett 12: 4133-4138, 2016.

78. Shin WS, Hong Y, Lee HW and Lee ST: Catalytically defective receptor protein tyrosine kinase PTK7 enhances invasive phenotype by inducing MMP-9 through activation of AP-1 and $\mathrm{NF}-\mathrm{\kappa B}$ in esophageal squamous cell carcinoma cells. Oncotarget 7: 73242-73256, 2016.

79. Juchniewicz A, Kowalczuk O, Milewski R, Laudański W, Dzięgielewski P, Kozłowski M and Nikliński J: MMP-10, MMP-7, TIMP-1 and TIMP-2 mRNA expression in esophageal cancer. Acta Biochim Pol 64: 295-299, 2017.

80. Kozłowski M, Laudański W, Mroczko B, Szmitkowski M, Milewski R and Łapuć G: Serum tissue inhibitor of metalloproteinase 1 (TIMP-1) and vascular endothelial growth factor A (VEGF-A) are associated with prognosis in esophageal cancer patients. Adv Med Sci 58: 227-234, 2013.

81. Zheng L, Yin J, Wang L, Wang X, Shi Y, Shao A, Tang W, Ding G, Liu C, Chen S, et al: Interleukin 1B rs16944 G>A polymorphism was associated with a decreased risk of esophageal cancer in a Chinese population. Clin Biochem 46: 1469-1473, 2013.

82. Shrivastava MS, Hussain Z, Giricz O, Shenoy N, Polineni R, Maitra A and Verma A: Targeting chemokine pathways in esophageal adenocarcinoma. Cell Cycle 13: 3320-3327, 2014.

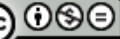

This work is licensed under a Creative Commons Attribution-NonCommercial-NoDerivatives 4.0 International (CC BY-NC-ND 4.0) License. 